\title{
Prognostic significance of chemokines CCL11 and CCL5 modulated by low-density lipoprotein cholesterol in colon cancer patients with normal body mass index
}

\author{
Caihua Wang ${ }^{1 \#}$, Yi Zou ${ }^{2 \#}$, Chi Pan ${ }^{3}$, Liming Shao ${ }^{1}$, Zonghui Ding ${ }^{4}$, Yunzhu Zhang ${ }^{1}$, Jun Ye ${ }^{1}$, Peiwei Li ${ }^{1}$, \\ Yuezhong Ren ${ }^{5}$, Chunpeng $\mathrm{Zhu}^{1}$ \\ ${ }^{1}$ Department of Gastroenterology, the Second Affiliated Hospital, Zhejiang University School of Medicine, Hangzhou, China; ${ }^{2}$ Department of \\ Pathology, the Second Affiliated Hospital, Zhejiang University School of Medicine, Hangzhou, China; ${ }^{3}$ Department of Surgical Oncology, the \\ Second Affiliated Hospital, Zhejiang University School of Medicine, Hangzhou, China; ${ }^{4}$ Department of Cancer Biology, Mayo Clinic Arizona, \\ Scottsdale, Arizona, USA; ${ }^{5}$ Department of Endocrinology and Metabolism, the Second Affiliated Hospital, Zhejiang University School of Medicine, \\ Hangzhou, China \\ Contributions: (I) Conception and design: C Zhu, Y Ren; (II) Administrative support: C Zhu; (III) Provision of study materials or patients: C Wang, C \\ Zhu; (IV) Collection and assembly of data: C Wang, Y Zou, C Pan, L Shao, Y Zhang; (V) Data analysis and interpretation: C Wang, Z Ding, J Ye, P \\ Li, C Zhu, Y Ren; (VI) Manuscript writing: All authors; (VII) Final approval of manuscript: All authors. \\ \#These authors contributed equally to this work. \\ Correspondence to: Chunpeng Zhu. Department of Gastroenterology, the Second Affiliated Hospital, Zhejiang University School of Medicine, \\ Hangzhou 310009, China. Email: zhuchunpeng@zju.edu.cn; Yuezhong Ren. Department of Endocrinology and Metabolism, the Second Affiliated \\ Hospital, Zhejiang University School of Medicine, Hangzhou 310009, China. Email: renyuez@zju.edu.cn.
}

Background: Many studies have shown an elevated level of cholesterol in colon tumors as compared to normal tissue. Obesity and high low-density lipoprotein cholesterol (LDL-C) are known risk factors for colon cancer. However, the role of LDL-C in colon cancer patients with normal body mass index (BMI) remains elusive.

Methods: Levels of serum cholesterol and oxysterols were quantified by ultra-performance liquid chromatography-tandem mass spectrometer (UPLC-MS/MS) from 129 individuals with normal BMI, including 32 with solitary polyp, 36 with multiple polyps, and 31 with adenocarcinoma as well as 32 healthy controls. In vitro, colon cancer cells were treated with LDL-C and assayed for chemokines via RNA-Seq and mitochondrial morphology via transmission electron microscopy and immunofluorescence. Additionally, correlation analysis was performed between LDL-C-induced chemokines and the overall survival of colon cancer patients from the Cancer Genome Atlas (TCGA), the Genotype-Tissue Expression (GTEx), and the Human Protein Atlas (HPA) database.

Results: The serum cholesterol level was significantly higher in colon adenocarcinoma patients with normal BMI than that in healthy controls $(\mathrm{P}<0.001)$. LDL-C potentiated colon cancer cell invasion and resistance to glucose-deprivation in vitro via chemokine-mediated signaling, mainly upregulation of CC chemokine ligand (CCL) 5 and downregulation of CCL 11. By analyzing the RNA expression data of colorectal cancer from TCGA, GTEx, and HPA, we demonstrated that the CCL5 level in colorectal adenocarcinoma tissues was significantly increased relative to adjacent normal tissues $(\mathrm{P}=0.01)$ while the CCL11 level was decreased $(\mathrm{P}=0.01)$. Both increased CCL5 and decreased CCL11 showed a negative correlation with the 5 -year overall survival in tumor node metastasis (TNM) stage II colon cancer patients ( $\mathrm{P}=0.0032,0.026$ for CCL5 and CCL11, respectively).

Conclusions: Our study supports the idea that LDL-C regulates the expression of CCL5 and CCL11 chemokines, which may have predictive values for survival in colon cancer patients with normal BMI, especially for patients in TNM stage II.

Keywords: Cholesterol; chemokines; colon cancer; overall survival; CCL5; CCL11 
Submitted Feb 14, 2020. Accepted for publication Nov 08, 2020.

doi: 10.21037/atm-20-1604

View this article at: http://dx.doi.org/10.21037/atm-20-1604

\section{Introduction}

Hypercholesterolemia promotes the incidence of colon cancer and indicates a poor overall prognosis (1-3). Altered cholesterol metabolism is emerging as an important process in cancer metabolism. In mammals, cholesterol is either absorbed from dietary sources or synthesized de novo in the liver, from which it is transported by apolipoproteins (lowdensity lipoprotein cholesterol, LDL-C) to the systemic circulation (4). LDL-C is a spherical particle with a diameter of $220 \mathrm{~nm}$ and a mass of $\sim 3,000 \mathrm{kDa}$. Each particle contains $~ 1,500$ molecules of cholesterol ester in an oily core that is shielded from the aqueous serum by a hydrophilic coat composed of $\sim 800$ molecules of phospholipids, $\sim 500$ molecules of unesterified cholesterol, and 1 molecule of a $500 \mathrm{kDa}$ protein, apoB (5). Cholesterol is essential for membrane biogenesis and cell proliferation (6), and both cholesterol and its metabolite are demonstrated to be vital for cancer progression. For instance, aberrant cholesterol ester accumulation was found in advanced prostate cancers with PTEN loss and PI3K/AKT activation (7). Cholesterolmetabolites, such as 27-hydroxycholesterol (27-OHC) could increase breast cancer metastasis (8). Although the pivotal role of cholesterol in colon cancer initiation, recurrence, and metastasis in obesity or overweight patients has been extensively studied (1), few studies have explored the role of cholesterol in colon adenoma and colon cancer with normal body mass index (BMI). However, retrospective studies revealed that patients with recurred colon cancer after curative surgery were generally with normal BMI and showed increased levels of cholesterol in colon tumors as compared to normal tissue (9). Several mechanisms are involved in the altered level of intracellular cholesterol: upregulation of rate-limiting enzyme of cholesterol synthesis, increased uptake of extracellular cholesterol by LDL receptor-mediated endocytosis, and decreased expression of cholesterol exporter (9). Recently, we demonstrated that LDL-C receptor expression levels were significantly higher in colon cancer tissues relative to adjacent normal tissues (10). It is unknown whether LDL-C play a vital role in colon cancer patients with normal BMI.

Colon cancer prognosis is largely dependent on the stage and histological grade. However, patients with TNM stage II colon cancers show significantly different clinical outcomes even if they have similar histopathologic features. For example, $50-60 \%$ of stage II colon cancer patients who undergo curative resection experience local recurrence or distant metastases $(11,12)$. Therefore, risk assessment is generally performed for stage II patients, and adjuvant chemotherapy is recommended for patients with high-risk features. However, the benefit of adjuvant chemotherapy does not improve survival by more than $5 \%$. According to the latest guidelines of colon cancer (NCCN guidelines Version 4. 2019), the high-risk features include poorly differentiated histology (exclusive of those that are microsatellite instabilityhigh), lymphatic/vascular invasion, bowel obstruction, perineural invasion, localized perforation, and close/ indeterminate/or positive margins. The current prognostic factors are largely dependent on the features of the primary tumor. However, the contributions of systematic metabolic abnormalities, such as cholesterol dyshomeostasis, to tumor recurrence and tumor metastasis are not fully assessed (13).

Growing evidence suggests that chronic inflammation, regulated by a complex network of chemokines and their receptors, intensively correlates with colon cancer incidence and prognosis (14). About $25 \%$ of cancers appear due to chronic infection or chronic inflammation, and all solid tumors contain an inflammatory microenvironment (15). Metabolic transformation has important regulatory functions in chronic inflammation, and inflammationinduced epigenetic switches promote tumorigenesis (16). Increased inflammation is associated with obesity which contributes to the occurrence and development of colon cancer. Epidemiological studies have outlined the interlink between serum cholesterol (hypercholesterolemia) and colorectal cancer incidence. The statin use was observed to reduce the incidence and cancer-related mortality of colorectal cancer (17-19). The underlying mechanisms of anticancer effect induced by statins are related to the regulation of immune response (20). However, the association of chemokines and serum cholesterol (whether cholesterol can induce chemokines or not, which chemokines can cholesterol induce) is poorly understood. We hypothesized that LDL-C might induce the alterations of chemokines to promote the progression of colon adenomatous polyps to adenocarcinoma. 
In this study, we quantified the levels of serum cholesterol and oxysterols in colon adenomatous polyps and adenocarcinoma patients with normal BMI (defined with BMI 18.5 to $24 \mathrm{~kg} / \mathrm{m}^{2}$ ). Our study also measured the alterations of chemokines and mitochondrial reactive oxygen species (ROS) as well as morphology changes in colon cancer cells treated with LDL-C. Furthermore, an analysis of correlation was performed between chemokines induced by LDL-C and overall survival of colon cancer patients. We present the following article in accordance with the MDAR checklist (available at http://dx.doi. org/10.21037/atm-20-1604).

\section{Methods}

\section{Serum cholesterol and oxysterols measurement}

The study was conducted in accordance with the Declaration of Helsinki (as revised in 2013) and was approved by the Hospital Institutional Review Board (2019ERR-450) of the Second Affiliated Hospital of Zhejiang University School of Medicine. Informed consent was taken from all the patients. Briefly, we collected serum samples from 129 individuals who completed colonoscopy, including 30 healthy controls, 32 solitary polyp, 36 multiple polyps, and 31 adenocarcinoma patients with normal BMI (defined with BMI 18.5 to $24 \mathrm{~kg} / \mathrm{m}^{2}$ ). Moreover, patient characteristics, including age, sex, BMI, hypertension, diabetes mellitus, current smoking status, liver function, serum triglycerides, and serum free fatty acids, were collected for baseline assessment.

The serum cholesterol and oxysterols were quantified by using ultra performance liquid chromatographytandem mass spectrometer (UPLC-MS/ MS), as previously described by McDonald et al. (21). In this study, cholesterol (CAS 57-88-5, C3045, Sigma-Aldrich), 22(R)hydroxycholesterol (22R-OHC, CAS 17954-98-2, H9384, Sigma-Aldrich), 22(S)-hydroxycholesterol (22S-OHC, CAS 22348-64-7, H5884, Sigma-Aldrich), 25-Hydroxycholesterol (25-OHC, CAS 2140-46-7, H1015, Sigma-Aldrich), 27-hydroxycholesterol (27-OHC, CAS 20380-11-4, $700021 \mathrm{P}$, avanti polar lipids), and $7 \alpha$-hydroxycholesterol (7a-OHC, CAS 566-26-7, 700034P, avanti polar lipids) were used as standard. The Waters ACQUITY UPLC was coupled to an AB Sciex Triple Quad TM 6500. Cholesterol and oxysterols were resolved with a binary solvent gradient using a BEH C8 column $(2.1 \mathrm{~mm} \times 100 \mathrm{~mm}, 1.7 \mu \mathrm{m}$, Waters). The mobile phases were (A) 70\% acetonitrile with $5 \mathrm{mM} \mathrm{NH} \mathrm{mHAc}_{4}$ (73594, Sigma-Aldrich) and (B) 1:1 isopropyl alcohol: acetonitrile with $5 \mathrm{mM} \mathrm{NH}_{4} \mathrm{OAc}$. The gradient was started at $0 \% \mathrm{~B}$ and ramped to $100 \% \mathrm{~B}$ over $2 \mathrm{~min}$, hold at $100 \% \mathrm{~B}$ for $1.5 \mathrm{~min}$, and returned to $0 \% \mathrm{~B}$ for a $2 \mathrm{~min}$. The flow rate was $0.5 \mathrm{~mL} / \mathrm{min}$, and the column was maintained at $50^{\circ} \mathrm{C}$. MS instrument was operated in scheduled multiple reaction monitoring mode.

\section{Cell culture}

Three colon cancer cell lines (RKO, SW480, and LoVo) were purchased from the Cell Bank of Type Culture Collection of the Chinese Academy of Sciences (Shanghai). SW480 cells were cultured in Leibovitz's L-15 medium, while RKO and LoVo cells were maintained in complete Eagle's minimum essential medium and F12K medium, respectively. Cells were supplemented with $10 \% \mathrm{FBS}, 100 \mathrm{U} / \mathrm{mL}$ penicillin, and $100 \mu \mathrm{g} / \mathrm{mL}$ streptomycin in a $5 \% \mathrm{CO}_{2}$ environment at $37^{\circ} \mathrm{C}$. All the cells were mycoplasma-free and routinely checked with the PCR Mycoplasma detection kit (K0103, HuaAn Biotechnology).

\section{Intracellular cholesterol and oxysterol measurement}

Colon cancer cell lines (RKO, SW480, and LoVo) were incubated with LDL-C $(100 \mu \mathrm{g} / \mathrm{mL})$ for $72 \mathrm{hrs}$, collected and washed with PBS. One $\mathrm{mL}$ of the 1:1 mixture of dichloromethane: methanol solution with $50 \mu \mathrm{g} / \mathrm{mL}$ butylated hydroxytoluene was added to the samples. Then, the samples were homogenized, flushed with in $\mathrm{N}_{2}$, placed in a $30^{\circ} \mathrm{C}$ ultrasonic bath for $10 \mathrm{~min}$, and centrifuged 3,500 rpm for $5 \mathrm{~min}$ at room temperature. The organic layer was collected and assayed for the intracellular cholesterol and oxysterol as stated in supplementary methods (Appendix 1).

\section{Measurement of cellular ROS}

Cellular ROS with or without LDL-C $(100 \mu \mathrm{g} / \mathrm{mL})$ treatment was detected using specific ROS probes by confocal microscope and flow cytometry. For flow cytometric measurement, cells were incubated with 2',7'-Di chlorodihydrofluorescein diacetate (DCFH-DA, $10 \mu \mathrm{M}$, D6883, Sigma) for $30 \mathrm{~min}$ at $37^{\circ} \mathrm{C}$, after which the cells were washed and suspended in ice-cold PBS and analyzed for fluorescence intensity using a $485 \mathrm{~nm}$ excitation beam (FACS ArrayBioanalyzer, BD biosciences). FlowJo v 7.6 quantified the mean fluorescence intensity. For confocal measurement, ROS measurement is assayed by DCFH-DA, 
4-amino-5-methylamino-2,7-difluorofluorescein (DAF-FM, D2321, Sigma), dihydroethidium (DHE, D7008, Sigma), MitoSOX TM Red mitochondrial superoxide indicator (MitoSOX Red, M36008, Invitrogen), Hydroxyl Radical and Peroxynitrite Sensor (HPF, H36004, Invitrogen), or mitochondria peroxy yellow 1 (MitoPY1, 4428, Tocris Bioscience) according to manufactures' instruction. Briefly, cells were loaded with DCFH-DA (10 $\mu$ M for 30 minutes), DAF-FM (10 $\mu \mathrm{M}$ for 30 minutes), DHE ( $5 \mu \mathrm{M}$ for 30minutes), MitoSOX Red (2.5 $\mu \mathrm{M}$ for 10 minutes), HPF (10 $\mu \mathrm{M}$ for 30 minutes), or MitoPY1(10 $\mu \mathrm{M}$ for 30 minutes), washed with ice-cold Hank's Balanced Salt Solution (HBSS, $\mathrm{pH}$ 7.2), and then observed under a Zeiss LSM710 laser confocal microscope (Carl Zeiss, Germany) equipped with Zen software to process the image.

\section{Transmission electron microscopy}

RKO, SW480, and LoVo colon cancer cells were incubated with or without LDL-C $(100 \mu \mathrm{g} / \mathrm{mL})$ for $72 \mathrm{hrs}$ and fixed in $2.5 \%$ glutaraldehyde in $0.1 \mathrm{M}$ sodium phosphate buffer overnight. The samples were treated with $1.5 \%$ osmium tetroxide, dehydrated with acetone, and embedded in durcupan resin. Samples were post-stained with lead citrate and examined in a TECNAI 10 electron microscope (Philips, The Netherlands) at $60 \mathrm{kV}$.

\section{Immunofluorescence}

The cellular mitochondrion was detected by MitoTracker ${ }^{\mathrm{TM}}$ Red FM (M22425, Invitrogen) according to the protocols of the suppliers. In brief, RKO cells were cultured on coverslips inside 12-well plate filled with Eagle's minimum essential medium with or without LDL-C $(100 \mu \mathrm{g} / \mathrm{mL})$ for $72 \mathrm{hrs}$, washed with pre-warmed $\operatorname{HBSS}\left(37^{\circ} \mathrm{C}\right)$, and incubated with pre-warmed staining solution containing Mito Tracker ${ }^{\mathrm{TM}}$ Red FM (100 nM) for 30 mins. Then cells were washed carefully with pre-warmed culture medium and fixed with $3.7 \%$ paraformaldehyde for $15 \mathrm{~min}$ at room temperature. Nuclei were counterstained with DAPI. All post-fixed sections were mounted and viewed under Zeiss LSM 710 laser confocal microscope.

\section{Transwell invasion assay}

Transwell assay was conducted with invasion chamber $(8-\mu \mathrm{m}$ pore size) (Corning Costar, Cambridge, MA, USA) coated with $40 \mu$ l Matrigel mixture (BD Biosciences, matrigel: serum-free culture medium=1:7) under the instructions of manufacturer. All colon cancer cell lines $\left(1 \times 10^{5}\right.$ cells $)$ were incubated with or without LDL-C $(100 \mu \mathrm{g} / \mathrm{mL})$, $\mathrm{N}$-acetylcysteine (NAC, $4 \mathrm{mM}$ ) or SkQ1 (100 nM) for indicated time at $37{ }^{\circ} \mathrm{C}$. The cells were stained with crystal violet, and observed under a phase-contrast microscope (Carl Zeiss, Axiovert-S100, Germany). The extents of invasion were analyzed by ImageJ software (NIH).

\section{RNA-Seq transcriptional profiling}

The RNA-Seq for whole genome-wide gene expression profiles of RKO, SW480, and LoVo colon cancer cells with or without LDL-C $(100 \mu \mathrm{g} / \mathrm{mL}) 72 \mathrm{hr}$ incubation was performed by Novogene (Beijing, China). Gene Ontology (GO) and KEGG pathways enrichment analysis of differentially expressed genes (DEGs) were implemented by the cluster Profiler R package, in which gene length bias was corrected.

\section{Survival analysis}

Kaplan-Meier plots summarize results from analysis of correlation between mRNA expression and patient survival from Human Protein Atlas database (http://www. proteinatlas.org) using best separation, as we previously reported (22). The cut-off values of CCL11 and CCL5 mRNA expression level were 1.01 FPKM and 21.02 FPKM, respectively. Patients were divided based on level of expression into one of the two groups "low" or "high". After balancing age, gender and tumor stage, the 5-year survival for patients with high expression or low expression and logrank $\mathrm{P}$ value were displayed.

\section{Statistical analysis}

All data were analyzed using the InStat software (GraphPad, CA, USA) and displayed as mean \pm SD. Two-tailed Student's $t$-test was used for statistical analysis, and significance was defined at ${ }^{* * *} \mathrm{P}<0.001,{ }^{* *} \mathrm{P}<0.01,{ }^{*} \mathrm{P}<0.05$.

\section{Results}

\section{Serum cholesterol level increases significantly in colon adenomatous polyp and adenocarcinoma patients with normal body-mass index}

Altered cholesterol metabolism and its metabolites such as 


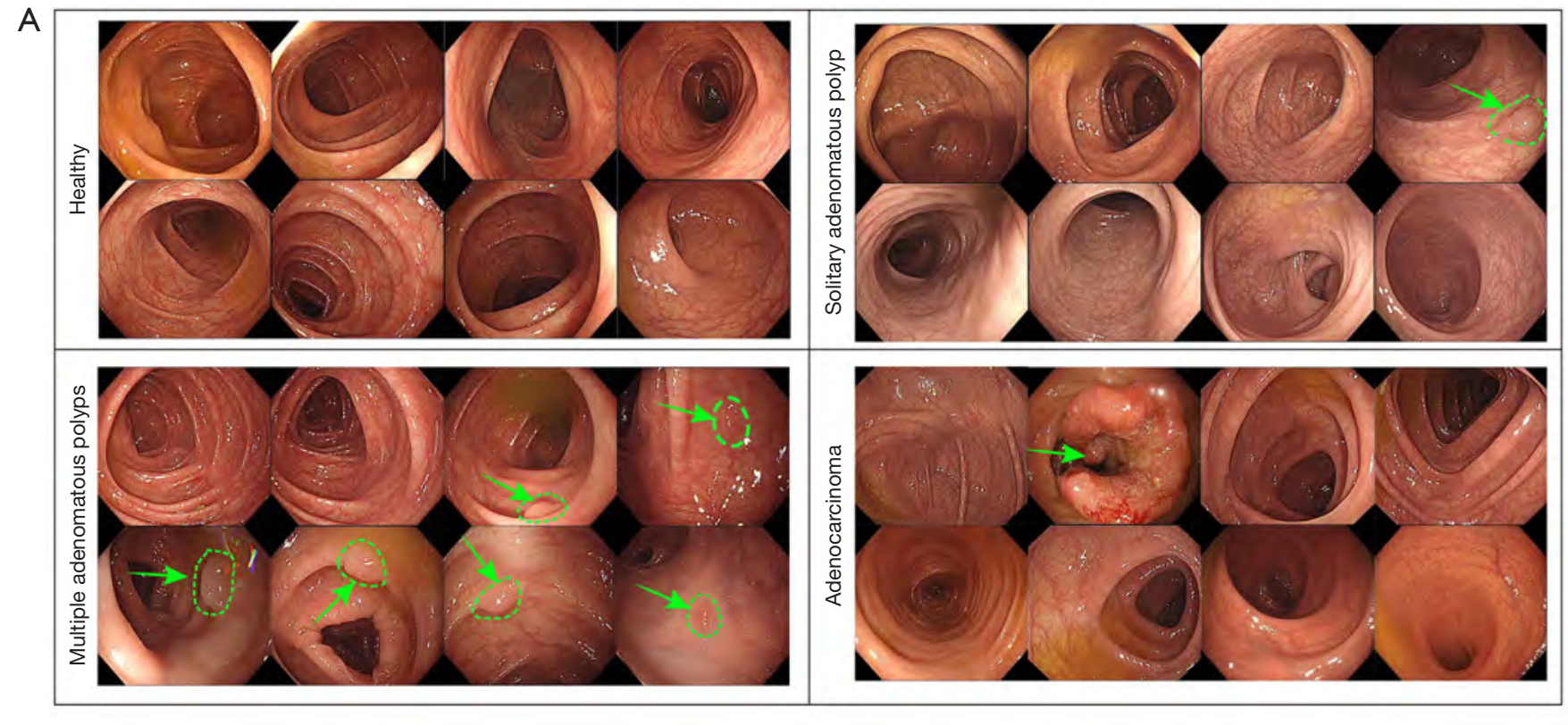

B

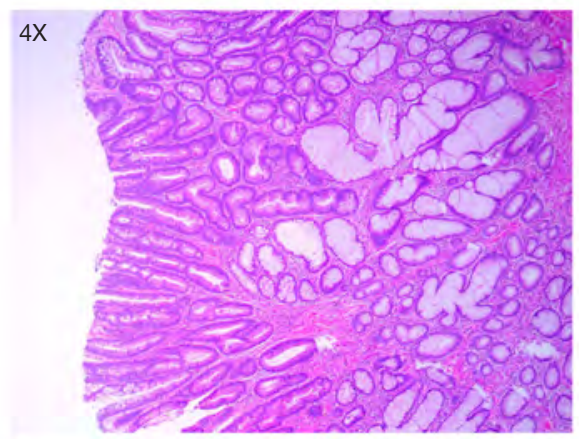

Adenocarcinoma

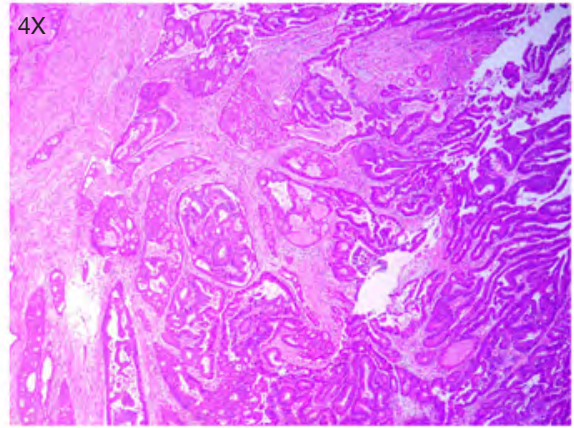

Figure 1 Clinical features of recruited patients. (A) Colonoscopy findings of healthy controls, solitary colon adenomatous polyp, multiple colon adenomatous polyps and colon cancer patients. The polyps or cancer locations were highlighted by green arrow and dotted oval. (B) The pathological structure of samples from colon adenoma and colon adenocarcinoma patients were stained with hematoxylin/eosin (HE). The colon adenoma was from solitary or multiple colon polyps patients.

oxysterols have been implicated in tumorigenesis and cancer metastasis. We measured the serum cholesterol and 5 extensively investigated oxysterols comprised of 22R-OHC, 22S-OHC, 25-OHC, 27-OHC, and 7 $\alpha-\mathrm{OHC}$, in 129 individuals with normal BMI, including 32 with solitary polyp, 36 with multiple polyps, and 31 with adenocarcinoma as well as 32 healthy controls using UPLC-MS/MS (Figures 1,2A,B, Figure S1). It is well appreciated that risk factors for colorectal cancer include smoking, the consumption of red and processed meats, alcohol consumption, diabetes mellitus, low levels of physical activity, metabolic syndrome, obesity/high BMI, and inflammatory bowel disease. Our data showed that there were no significant differences in multi-factors, including age, sex, BMI, hypertension, diabetes mellitus, current smoking, liver function, serum triglycerides, and serum free fatty acids of recruited patients (Table 1). As shown in Figure 2C, levels of serum cholesterol, 27-OHC, and 7 $\alpha-\mathrm{OHC}$ were significantly increased in adenomatous polyp(s) and adenocarcinoma patients than that in healthy controls $(\mathrm{P}<0.001)$. Of note, the serum cholesterol level was approximately 1,000 times higher than those of the serum oxysterols.

As serum cholesterol is largely dependent on serum LDL-C level, we thus evaluated the effect of LDL-C on the production of oxysterols in colon cancer cells. It showed that the levels of $27-\mathrm{OHC}, 7 \alpha-\mathrm{OHC}$, and $25-\mathrm{OHC}$ were 


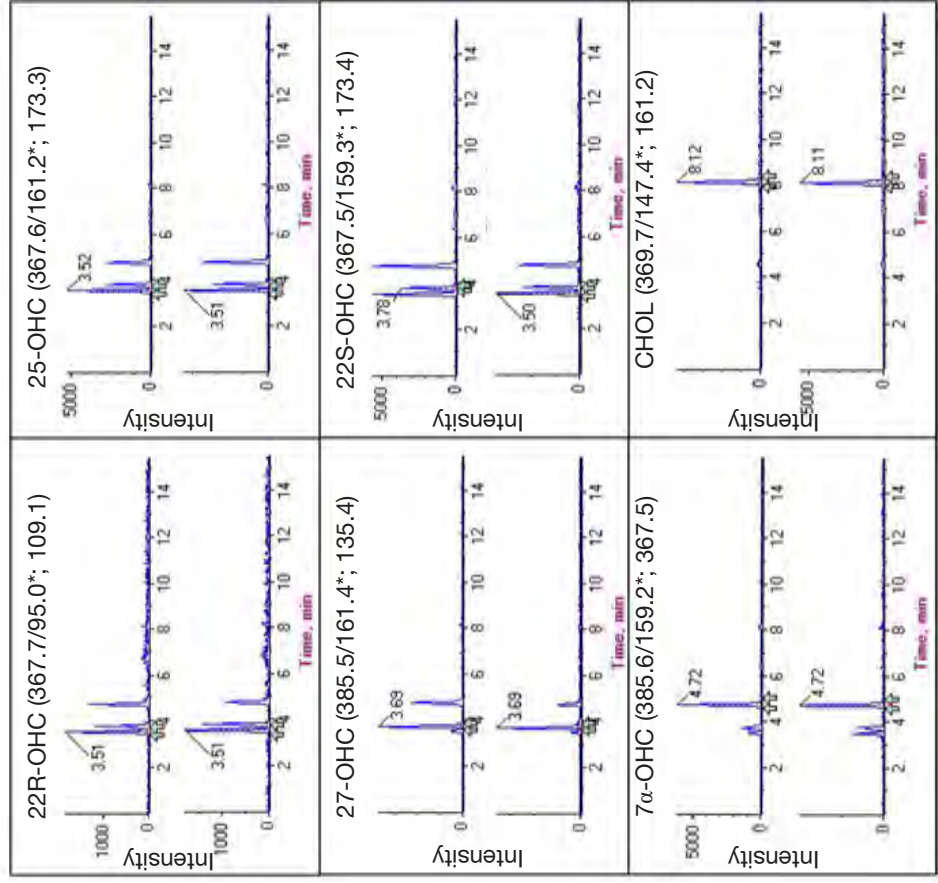

$\infty$

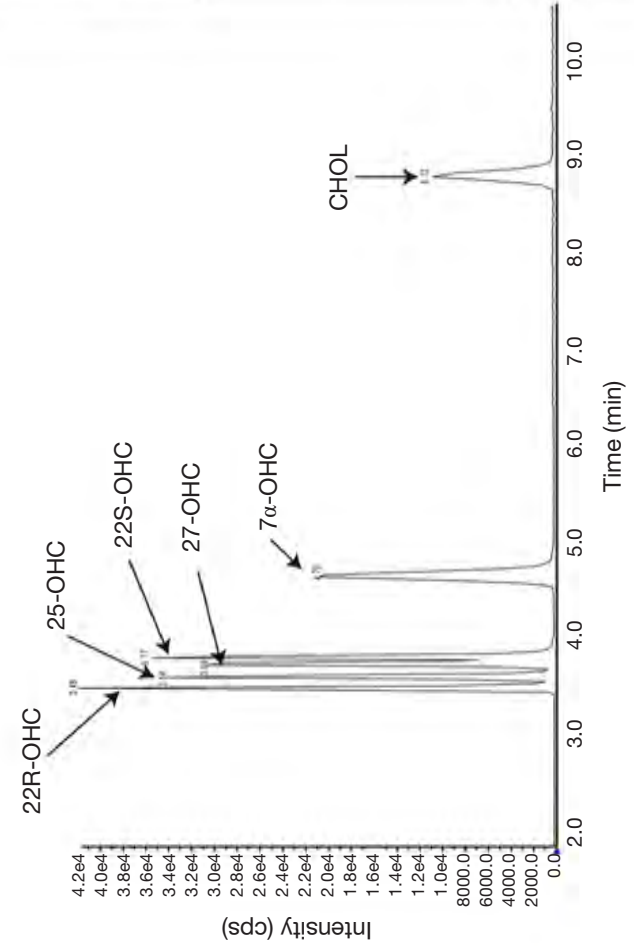

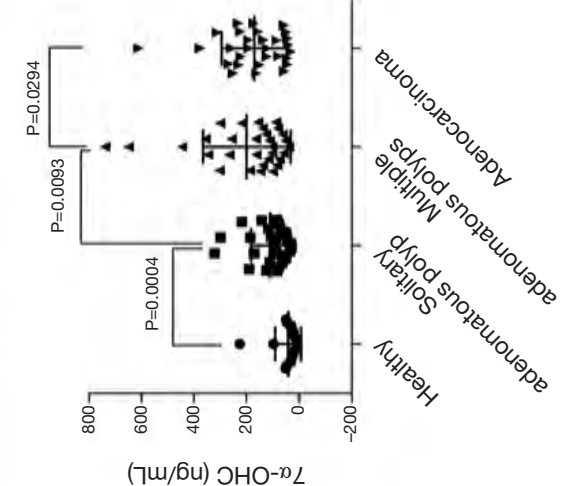
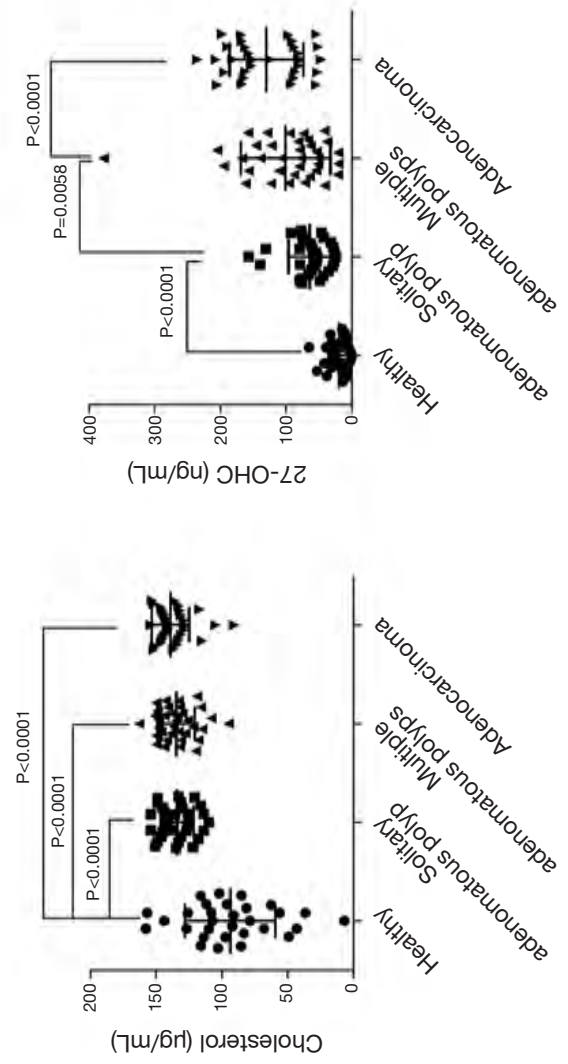

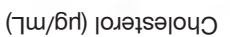

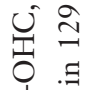

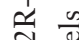

은

承

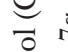

焉

范

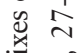

范

突

颉

Ч

苞

o

O

离

궁

这容

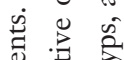

를

范

善产

氜

要

¿

월

8 㟔.

西

ล.

तो की की

范

낭

๑ิ

$\nsubseteq u$

:

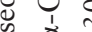

गृ

它

¿

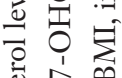

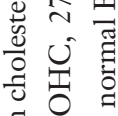

更

㲾

论

N

O 
Table 1 Baseline characteristics of participants in this study

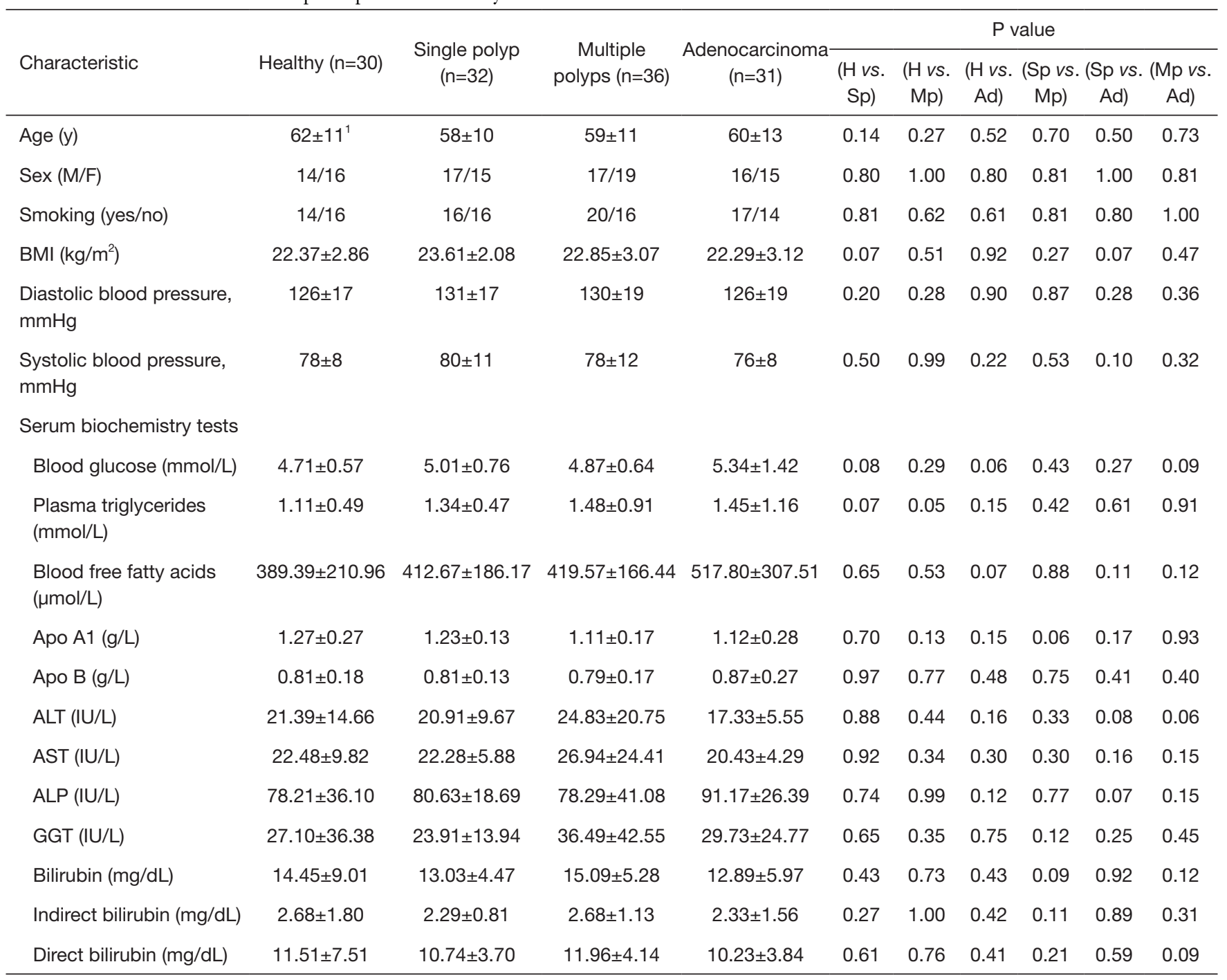

Multi-factors, including age, sex, body mass index, hypertension, diabetes mellitus, current smoking, liver function, serum triglycerides, and serum free fatty acids of recruited participants were measured. ${ }^{1}$, mean $\pm S D$ (all such values). ApoA1, apolipoprotein A1; ApoB, apolipoprotein B; ALT, alanine aminotransferase; AST, aspartate aminotransferase; ALP, alkaline phosphatase; GGT, $\gamma$-glutamyl transferase; $\mathrm{H}$, healthy; $\mathrm{Sp}$, single polyp; Mp, multiple polyps; Ad, adenocarcinoma.

significantly increased in RKO, SW480, and LoVo colon cancer cells after incubation with LDL-C (Figure S2). Therefore, the results suggested that the elevated oxysterols might be the results of increased LDL-C.

\section{Colon cancer cells with LDL-C incubation have elevated mitochondrial ROS levels and fissed mitochondria}

As oxysterols are largely dependent on the oxidation of cholesterol, we analyzed the redox status indicated by ROS specific probes detected by confocal microscopy and flow cytometry. LDL-C dramatically increased cellular ROS level and maintained at high levels for 60 minutes (Figure $3 A, B)$. Moreover, we detected the ROS composition and distribution by available ROS probes (Figure 3C). DCFHDA fluorescence mainly reflects the total ROS level, which was much higher in cells incubated with LDL-C. The intramitochondrial superoxide probed by Mitosox RED and mitochondrial hydrogen peroxide indicated by MitoPY1 were also significantly increased by LDL-C treatment. 


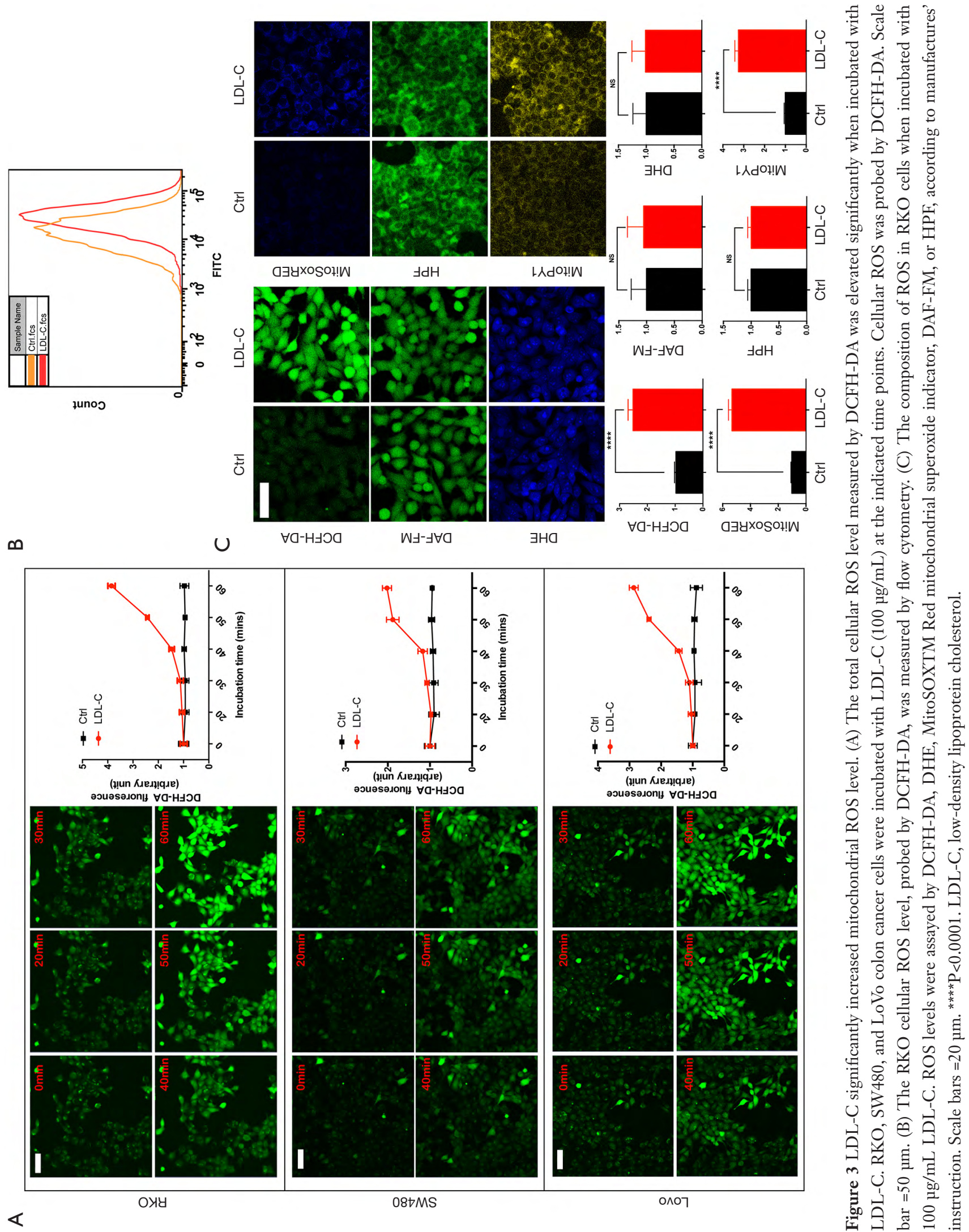


A

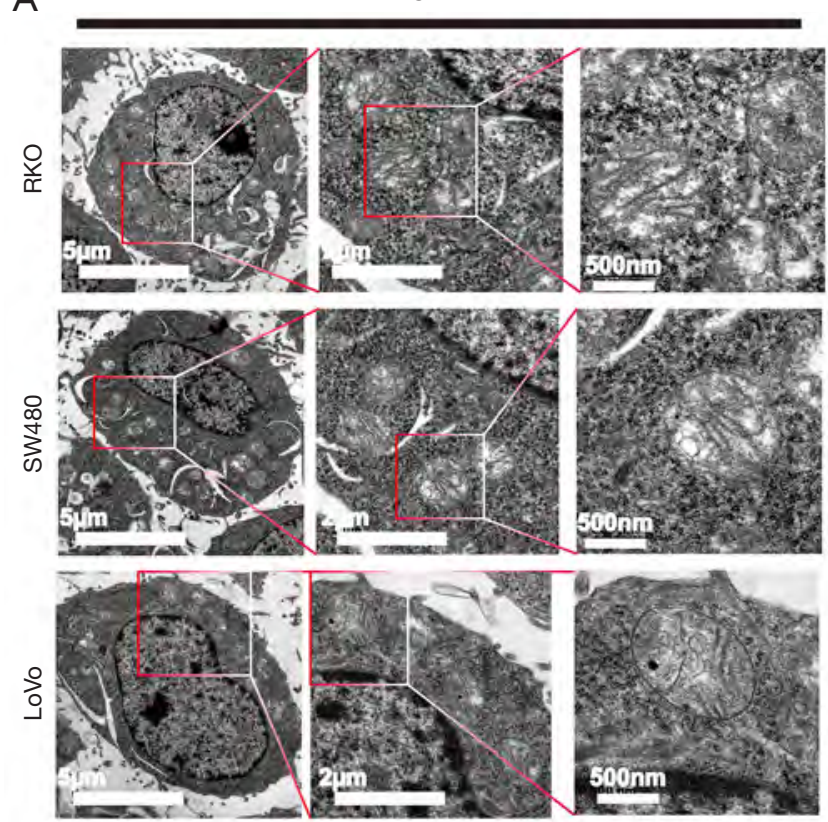

B

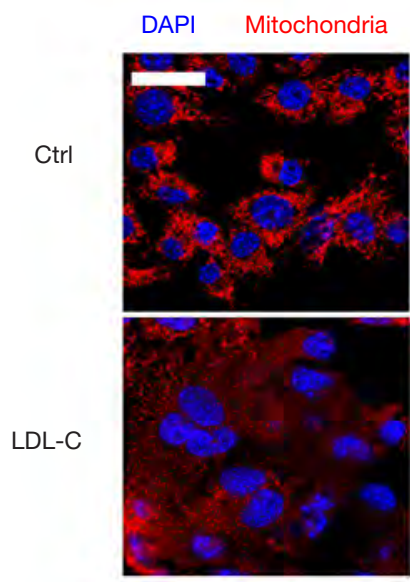

Mitochondria

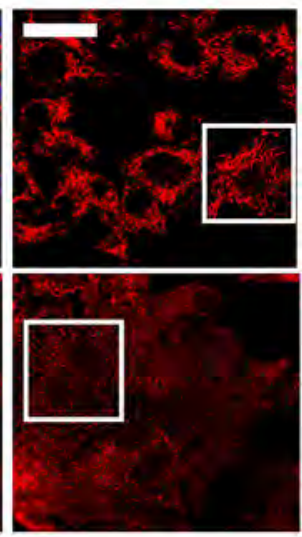

LDL-C
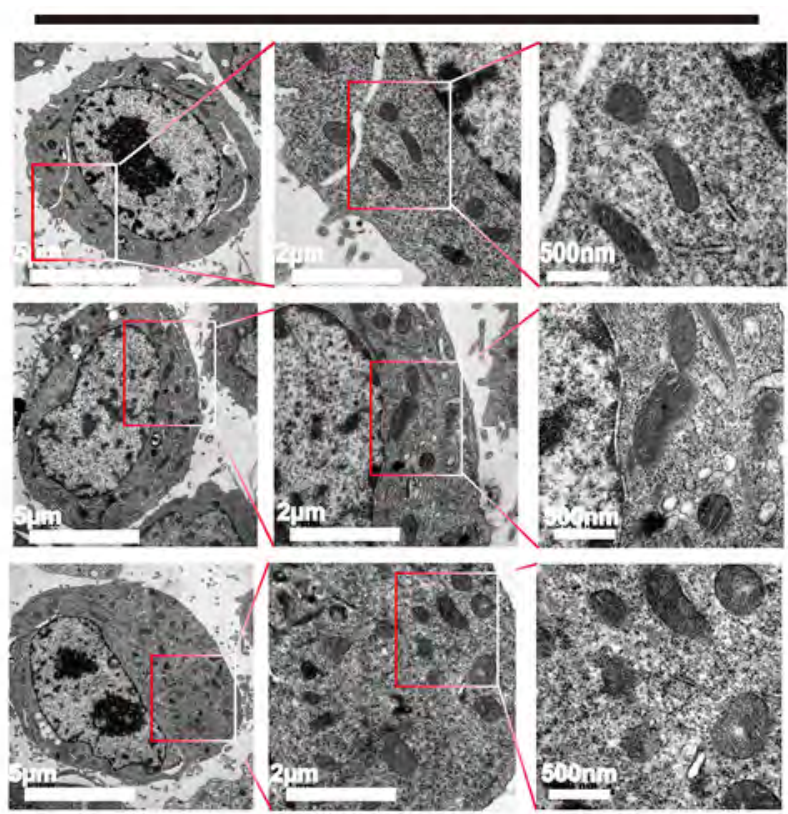

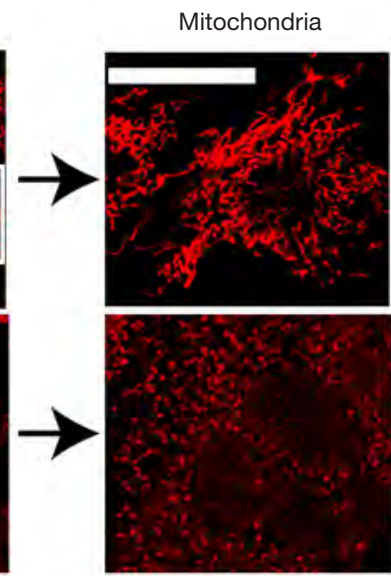

Figure 4 LDL-C induced changes in mitochondrial morphology. (A) Representative photographs of cellular mitochondria by transmission electron microscopy. RKO, SW480, and LoVo cells were incubated with or without LDL-C (100 $\mu \mathrm{g} / \mathrm{mL})$ for 72 hrs. (B) Representative confocal images of mitochondrial morphology were detected by MitoTracker ${ }^{\mathrm{TM}}$ Red FM in RKO cells. Scale bar $=10 \mu \mathrm{m}$. LDL-C, lowdensity lipoprotein cholesterol.

However, the levels of cellular hydroxyl radical and peroxynitrite (indicated by HPF fluorescence), the extramitochondrial superoxide (reflected by DHE fluorescence) and nitric oxide (indicated by DAF-FM fluorescence) were comparable in cells with and without LDL-C incubation. These results showed that LDL-C mainly induced mitochondrial superoxide and hydrogen peroxide.

Mitochondria are the main source of ROS within most mammalian cells (23). Mitochondrial structures can dynamically change between fissed morphologies (discrete ovoid structures) and fused morphologies (elongated tubular networks). We further detected the morphology of mitochondria by transmission electron microscopy. The mitochondria in colon cancer cell lines (RKO, SW480, and LoVo) were predominantly fused morphologies with lucentswelling matrix as reviewed by Arismendi-Morillo (24). When incubated with LDL-C, the mitochondria structure changed to condensed small morphologies (Figure 4A). 
Furthermore, the morphology of mitochondria indicated by MitoTracker RED FM was also changed from tubular shape to spherical or elliptical pattern after LDL-C incubation (Figure 4B). Interestingly, the condensed mitochondria have been demonstrated to be related to hypoxia-tolerance and adequate ATP production (24), and fragmented mitochondria have increased ROS level in tumorinfiltrating NK cells (25). Taken together, our data showed that LDL-C incubation increased mitochondrial ROS level and resulted in the morphological changes of mitochondria.

\section{LDL-C promotes colon cancer cell invasion and resistance to glucose deprivation}

To determine the effect of LDL-C on cell invasion, colon cancer cells (RKO, SW480, and LoVo) were incubated with or without LDL-C and analyzed using the Transwell invasion assay. Compared with the control group, colon cancer cells incubated with LDL-C had significantly increased invasion potential, which was inhibited by antioxidants such as NAC or SkQ1 (Figure 5A). LDL-C significantly prolonged the survival time of colon cancer cells under glucose depletion (Figure 5B). These results showed that LDL-C played a vital role in colon cancer cell invasion and resistance to glucose deprivation.

\section{LDL-C downregulates $R N A$ level of CCL11 and upregulates $R N A$ level of CCLS}

To explore genes and gene networks that are regulated by LDL-C, we performed RNA-seq analysis of RKO, SW480, and LoVo cells with or without LDL-C incubation. Using false discovery rate (FDR) $<0.05$ and fold change $>2$ as the significant cutoffs, we found 655,207 , and 258 DEGs in RKO, SW480, and LoVo, respectively. To further understanding the function of these DEGs, gene ontology (GO) and KEGG term enrichment analysis were performed. For genes that were up-regulated in LDL-C incubation group, the G-protein coupled receptor (GPCR) signaling, chemokine-mediated signaling, and integral component of serum membrane were significantly enriched GO terms (Figure 6A). On the other hand, linolenic acid metabolism was the most significantly enriched KEGG term (Figure S3A). For genes that were down-regulated in LDL-C incubation group, protein processing in the endoplasmic reticulum and cell cycle were significantly enriched KEGG terms (Figure S3B). Additionally, protein serine/threonine kinase activity, protein phosphorylation, and related signaling such as ERK1/ERK2 cascade and MAPK pathway were significantly enriched GO terms (Figure S4). Of note, chemokines and chemokine-mediated signaling were among the highly enriched GO categories in the up-regulated DEGs.

In general, chemokines, produced by various lymphoid and nonlymphoid cells, are assigned to several groups on the basis of their major biological functions as well as structural criteria. We further analyzed the $\mathrm{C}-\mathrm{C}$ motif ligand subfamily (CCL), CXC ligand subfamily (CXCL), and CX3C ligand subfamily (CX3CL) as well as their related chemokine receptors (Figure 6B, Figures S5-S7). As shown in Figure 6B, LDL-C upregulated RNA levels of CCL5 and downregulated CCL11 expression. Moreover, we measured the RNA expression level of CCL11 and CCL5 in colon cancer patients from gene expression profiling interactive analysis 2 (GEPIA 2, http://gepia2.cancer-pku.cn/index. $\mathrm{html}$ ) and found that the CCL5 expression level in colon and rectal adenocarcinoma tissues was significantly higher than that in normal tissues (matched TCGA normal and GTEx data), while the CCL11 level decreased (Figure 6C).

\section{Decreased CCL11 and increased CCL5 expression levels in tumor tissues show a negative correlation with the 5-year overall survival of TNM stage II colon cancer patients}

High chemokines concentrations, such as CXCL10, might be an independent marker for predicting hepatic metastasis and correlate with poor survival in colorectal cancer (11). We detected the RNA expression levels of CCL11 and CCL5 in colon cancer tissues from GEPIA 2. We found that the RNA expression level of CCL11 was significantly lower in colon cancer and rectal cancer tissues than that in normal tissues (Figure 7A). The CCL5 RNA expression was dramatically higher in colon cancer and rectal cancer tissues compared with normal tissue, although there was no significant statistical difference in the rectal cancer group (Figure $7 B$ ). Moreover, by analyzing the mRNA expression level of CCL11 or CCL5 and survival data of colon cancer patients from Kaplan-Meier plotter in the Human Protein Atlas database (HPA, http://www.proteinatlas.org), we found that a lower expression of CCL11 or a higher expression of CCL5 was negatively correlated with 5-year overall survival in TNM stage II colorectal cancer patients (Figure 7C,D and Figure S8). It suggested that decreased CCL11 or increased CCL5 RNA expression level might be useful prognostic markers for relatively early-stage colon cancer patients, especially TNM stage II. 
A
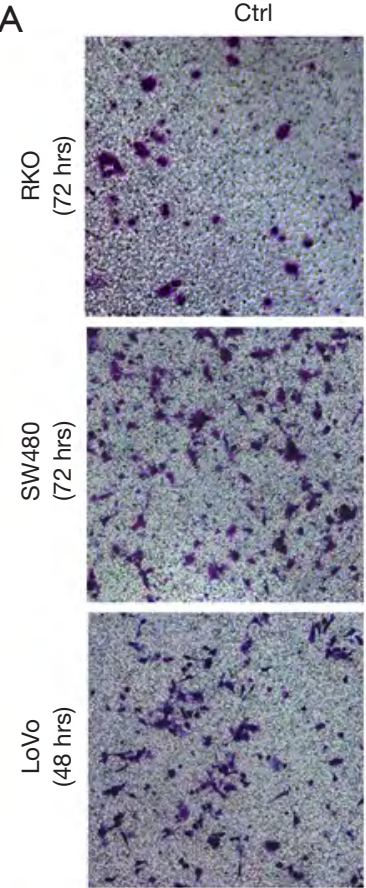

RKO

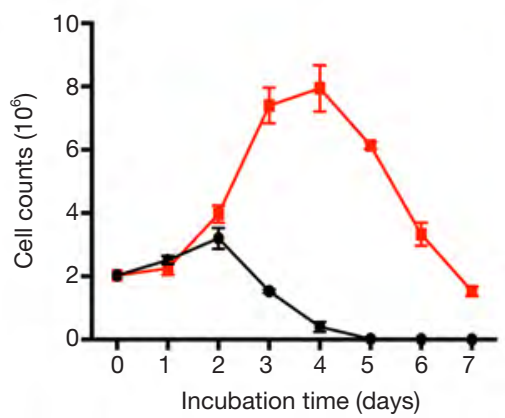

LDL-C
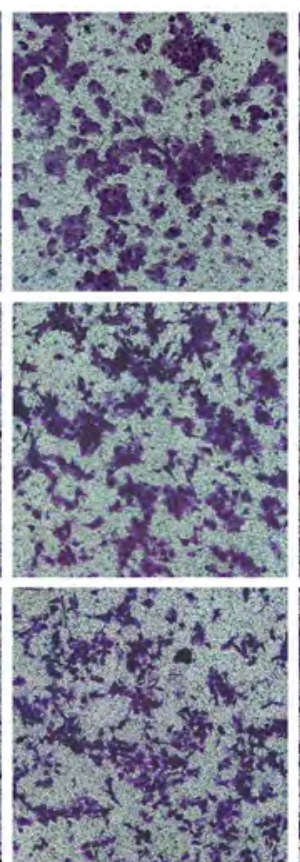

LDL-C+NAC
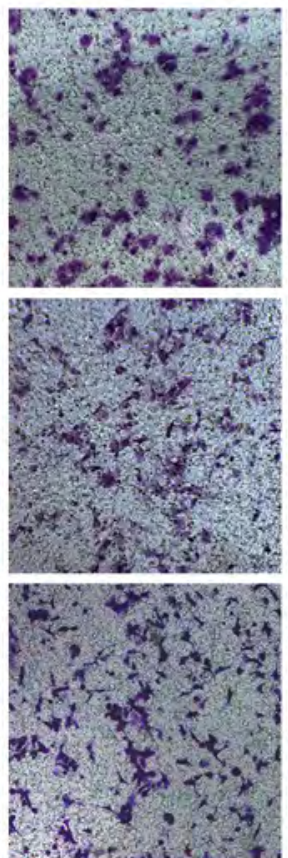

SW480
LDL-C+SkQ1
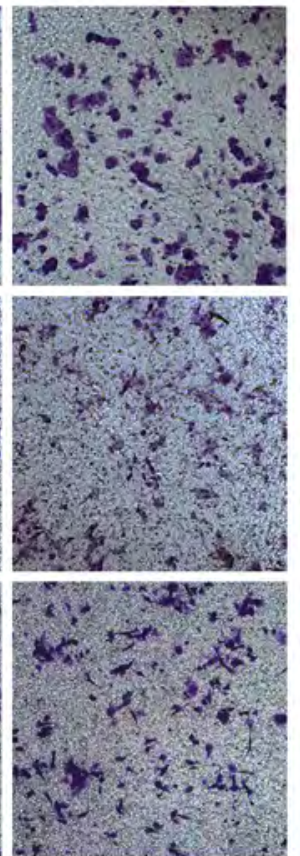

LoVo
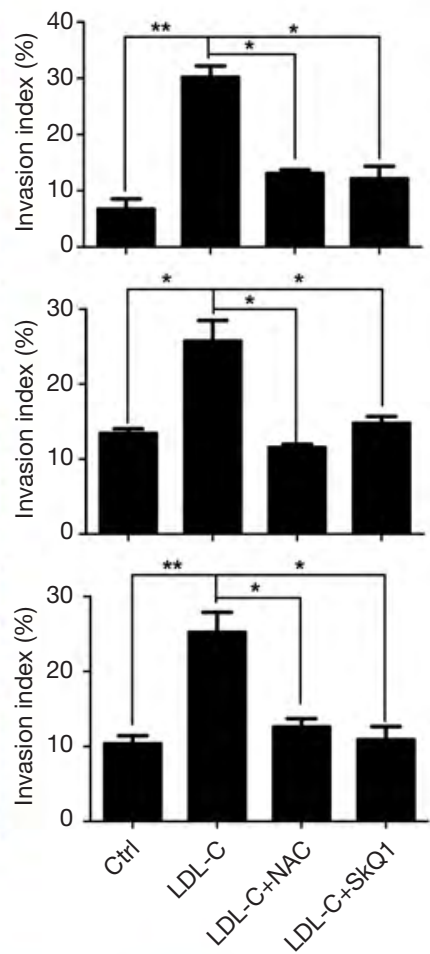
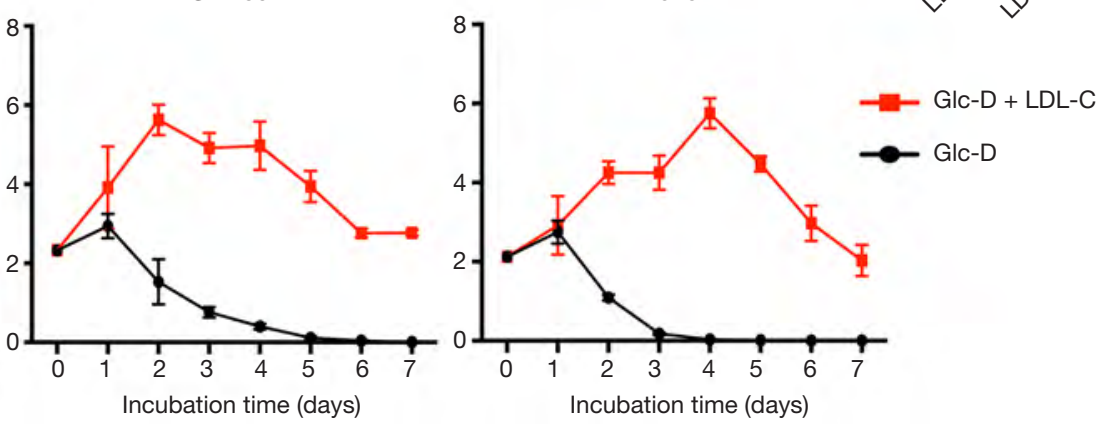

Figure 5 LDL-C significantly increased the cell invasion ability and resistance to glucose-deprivation. (A) RKO, SW480, and LoVo cells were incubated with LDL-C $(100 \mu \mathrm{g} / \mathrm{mL})$, NAC $(4 \mathrm{mM})$ or SkQ1 $(100 \mathrm{nM})$. Representative microscopic images of cells that migrated through the transwell in the migration assay. (Giemsa stain, magnification $\times 200$ ). Adjacent histograms represent the invasion index of these cells under indicated conditions. ${ }^{* *} \mathrm{P}<0.01,{ }^{*} \mathrm{P}<0.05$. (B) The cell proliferation profile of RKO, SW480, and LoVo cells was generated by incubation with glucose-deprivation medium (Glc-D), or glucose-deprivation medium with $100 \mu \mathrm{g} / \mathrm{mL}$ LDL-C (Glc-D + LDL-C). LDL-C, low-density lipoprotein cholesterol.

\section{Discussion}

Colon cancer is strongly associated with chronic inflammation and abnormal cholesterol metabolism. Herein, we demonstrated that serum cholesterol level was significantly elevated in colon adenomatous polyp and colon adenocarcinoma patients with normal BMI. LDL-C induced downregulation of CCL11 expression and upregulation of CCL5 expression, which were both negatively correlated with the 5-year overall survival of TNM stage II colon cancer patients.

Cholesterol is the main structural component of cell membranes, contributing to the unique biophysical properties of the lipid raft microdomains which regulate phosphorylation cascades originating from membranebound proteins, such as GPCR. Abnormal cholesterol metabolism might affect various cellular events and 
A

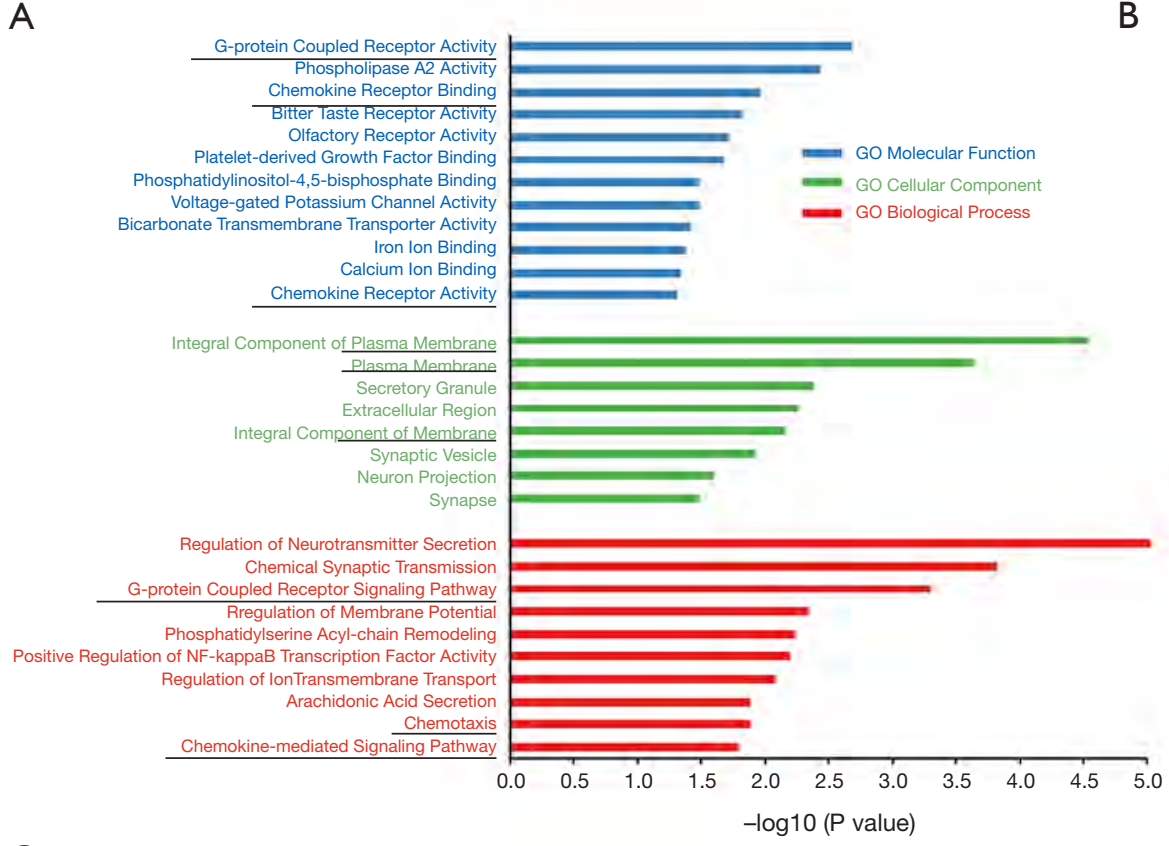

C

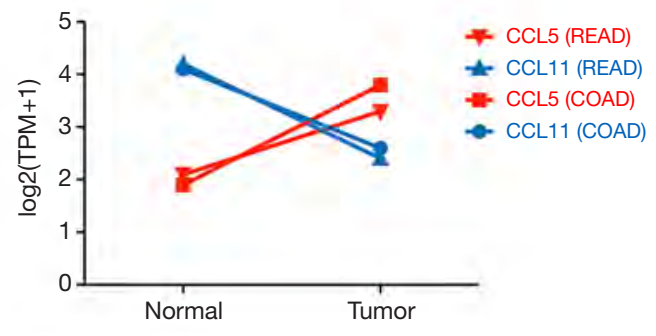

B

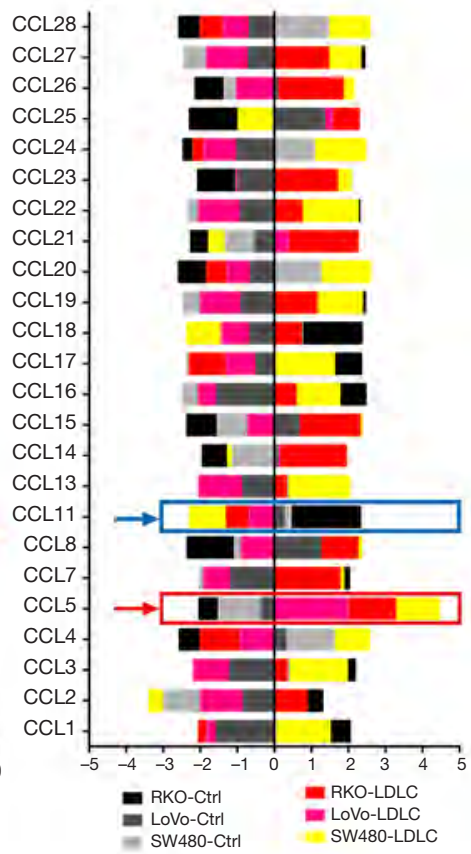

Figure 6 Significantly enriched GO terms $(\mathrm{P}<0.05)$ in the up-regulated genes. (A) GO terms belonging to molecular functions, cellular components, and biological processes were shown in blue, green, and red, respectively. GO terms were sorted based on $\mathrm{P}$ values. (B) The RNA expression changes of CCL chemokine family when incubated with LDL-C (100 $\mu \mathrm{g} / \mathrm{mL})$. In members of the CCL family, CCL5 was upregulated (highlighted by red rectangle box) while CCL11 was downregulated (highlighted by blue rectangle box). (C) The RNA expression level of CCL5 in colon and rectal adenocarcinoma tissues was higher than that in normal tissues (matched TCGA normal and GTEx data), while the CCL11 level decreased. Data from GEPIA 2 (http://gepia2.cancer-pku.cn/\#analysis). COAD, colon adenocarcinoma; READ, rectum adenocarcinoma; LDL-C, low-density lipoprotein cholesterol.

impair homeostasis $(26,27)$. Our RNA-seq data showed cell membrane and GPCR could be regulated by LDL-C in colon cancer cells. Moreover, increased intracellular cholesterol levels shut down cholesterol synthesis and facilitate its export via activation of LXR receptors by oxysterols (28). Oxysterols, 27 -carbon derivatives of cholesterol created by enzymatic or radical oxidation, play an important role in malignancies (29). Recently, a number of studies showed that increased levels of oxysterols, such as $7 \alpha-\mathrm{OHC}$ and $27-\mathrm{OHC}$, can promote cancer progression via combining with oxysterol receptors (8). Herein, we showed LDL-C significantly increased mitochondrial ROS, which could induce the oxysterols production (such as $27-\mathrm{OHC}, 7 \alpha-\mathrm{OHC}$, and $25-\mathrm{OHC}$ ) via radical oxidation. Consequently, the pathologic role of cholesterol in colon cancer might be attributed to the impact on biophysical properties of cellular membrane receptors such as GPCR and the influence of oxysterol production via ROS.

Tumor microenvironment is enriched with cholesterol, and the important role of cholesterol in cell immune response has received considerable critical attention. For example, Ma et al. demonstrated that cholesterol 
A

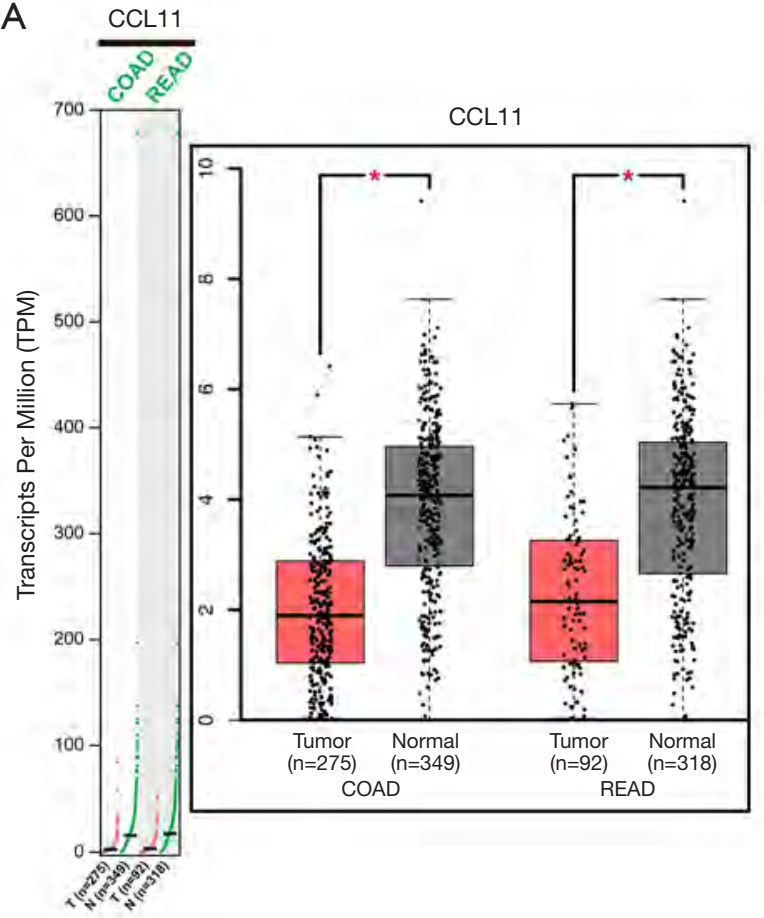

C

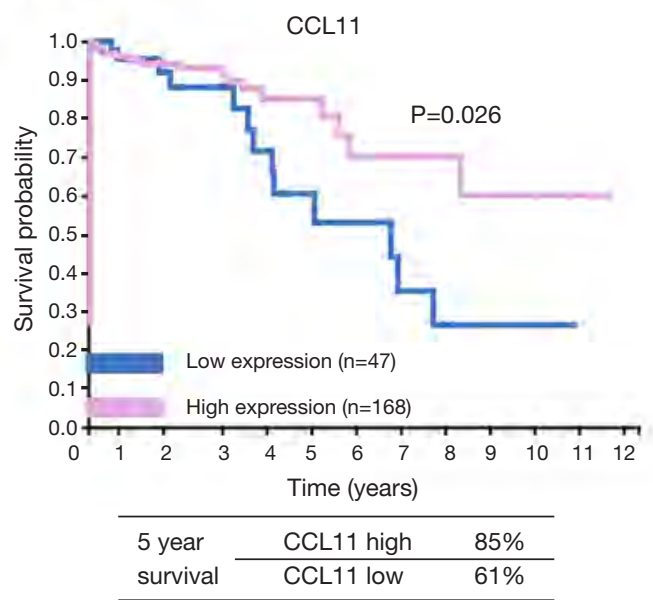

B $\quad$ CCL5

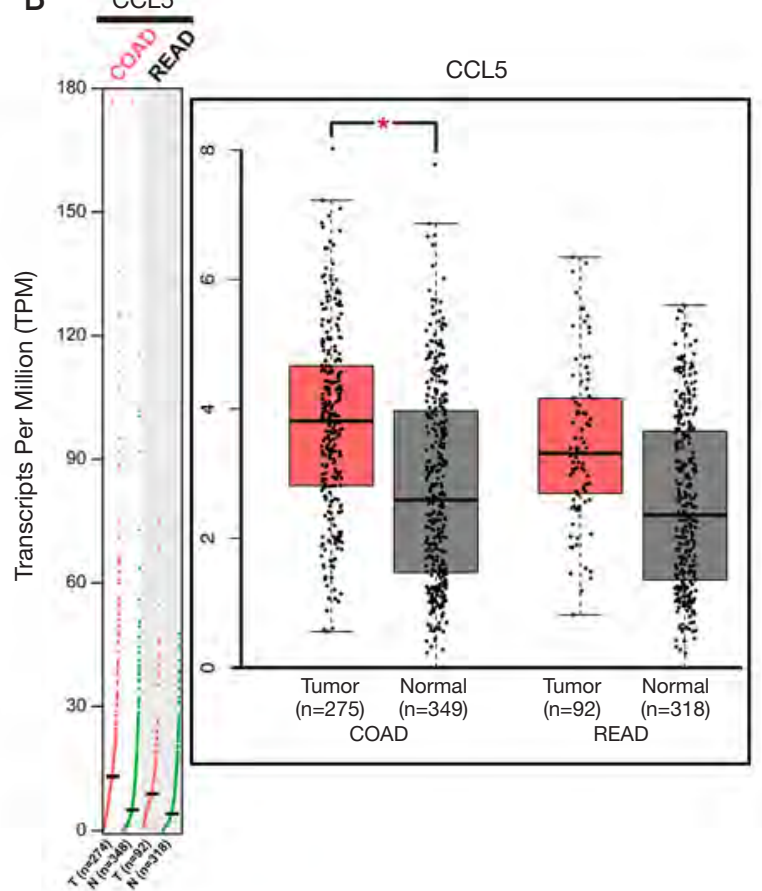

D

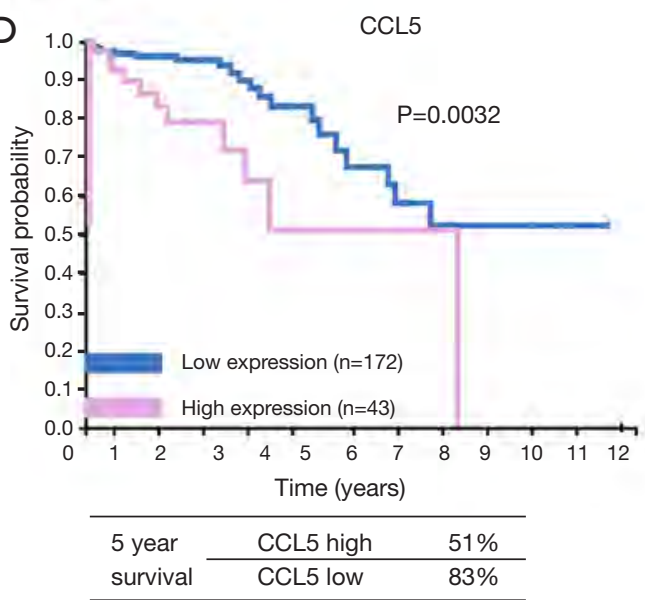

Figure 7 The decreased CCL11 and increased CCL5 were negatively associated with 5-year overall survival of colorectal cancer patients. (A) The RNA expression level of CCL11 in colon adenocarcinoma and rectal adenocarcinoma tissues was lower than that in normal tissues. Data from GEPIA 2. ${ }^{*} \mathrm{P}=0.01$. (B) The RNA expression level of CCL5 in colon adenocarcinoma tissues was higher than that in normal tissues. Data from GEPIA 2. ${ }^{*} \mathrm{P}=0.01$. (C) The KM plotter was used to analyze the relationship between mRNA expression level of CCL11 and 5-year overall survival of colorectal cancer patients. Decreased CCL11 was negatively associated with 5-year overall survival of TNM stage II colorectal cancer patients (P value $=0.026$, the cut-off value was 1.01 FPKM). Data from HPA database. (D) Increased CCL5 level was significantly associated with worse 5 -year overall survival of TNM stage II colon cancer patients ( $\mathrm{P}$ value $=0.0032$, the cut-off value was 21.02 FPKM). Data from HPA database. COAD: colon adenocarcinoma; READ: rectum adenocarcinoma; GEPIA 2: http://gepia2.cancerpku.cn/\#analysis; HPA: http://www.proteinatlas.org. 
could induce $\mathrm{CD} 8^{+} \mathrm{T}$ cell exhaustion in the tumor microenvironment (30) and Yang et al. argued that reduced cholesterol could potentiate the anti-tumor response of $\mathrm{CD}^{+} \mathrm{T}$ cells (31). Moreover, increased accumulation of cholesterol in cells during acute and chronic inflammation mediated by cytokines was observed in primates and humans. Inflammation, mediated by TNF- $\alpha$, IL-1, or IL-6, can decrease cholesterol clearance by inhibiting lipoprotein lipase (32). Enhanced LDL-C oxidation has also been documented during infection and inflammation (33). In this study, we found that LDL-C downregulated of CCL11 and upregulated CCL5 in colon cancer cells. Chemokines can be classified into inflammatory chemokines, homeostatic chemokines, and dual chemokines. Inflammatory chemokines are induced by inflammatory processes, while homeostatic chemokines are constitutively present in some, primarily lymphoid, organs. Dual chemokines are expressed in both homeostatic and inflammatory situations. CCL5 is an inflammatory chemokine, while CCL11 belongs to dual chemokines. CCL11 displays chemotactic activity for eosinophils, but not mononuclear cells or neutrophils via interacting with agonistic receptors (CCR3, CCR5) and antagonistic receptors (CXCR3, CCR2). CCL5 functions as a chemoattractant for blood monocytes, memory $\mathrm{T}$ helper cells, and eosinophils via interacting with agonistic receptors (CCR1, CCR3, and CCR5) (34). As shown in Figure S9, CCR3 and CCR2 are associated with BDCA4 ${ }^{+}$ dendritic cells, $\mathrm{CD} 33^{+}$myeloid cells, and $\mathrm{CD} 14^{+}$monocytes cells, while CCR5 activates BDCA4 ${ }^{+}$dendritic cells and $\mathrm{CD}^{+} \mathrm{T}$ cells, and CXCR3 is associated with $\mathrm{BDCA}^{+}$ dendritic cells. The downregulation of CCL11 and upregulation of CCL5 could recruit and activate BDCA4 $4^{+}$ dendritic cells, $\mathrm{CD} 33^{+}$myeloid cells, and $\mathrm{CD} 14^{+}$monocytes. Dendritic cells, often called "nature's adjuvants" and thus have become the natural agents for antigen delivery. They are at the center of the immune system owing to their ability to control both immune tolerance and immunity $(35,36)$. Interestingly, recent studies demonstrated that $\mathrm{BDCA}^{+}$dendritic cells, such as plasmacytoid DCs, were shown to correlate with poor prognosis in both ovarian and breast cancers $(37,38)$. In addition, $\mathrm{CD} 33^{+}$myeloid cells had an obvious immune inhibitory effect on T cells in lung cancer (39). Moreover, CD $14^{+}$monocytes (mainly CD $14^{+}$HLA-DRlow/- monocytes) showed an immunosuppressive effect in multiple cancers, including lymphoma, multiple myeloma, glioblastoma, prostate cancer, and renal cell carcinoma (40).

To summarize, our study revealed the novel role of cholesterol in regulating local chemokines such as CCL5 and CCL11 in the colon cancer. Our data suggests that CCL11 and CCL5 levels in tumor tissues might be potential prognostic markers for colon cancer, especially in TNM stage II patients.

\section{Acknowledgments}

Funding: This work was supported by research grants from China Natural Sciences Foundation projects (81602516, 81802881 ) and Zhejiang Provincial National Science Foundation of China (LY20H160031, LY18H160009, LY16H160031). The funding bodies had no role in the design of the study and collection, analysis, and interpretation of data and in the writing of the manuscript.

\section{Footnote}

Reporting Checklist: The authors have completed the MDAR checklist. Available at http://dx.doi.org/10.21037/atm-201604

Data Sharing Statement: Available at http://dx.doi. org/10.21037/atm-20-1604

Conflicts of Interest: All authors have completed the ICMJE uniform disclosure form (available at http://dx.doi. org/10.21037/atm-20-1604). The authors have no conflicts of interest to declare.

Ethical Statement: The authors are accountable for all aspects of the work in ensuring that questions related to the accuracy or integrity of any part of the work are appropriately investigated and resolved. The study was conducted in accordance with the Declaration of Helsinki (as revised in 2013). The protocols for serum cholesterol and oxysterols measurements of different patients were approved by the Committee of Clinical Experimental Centre at the Second Affiliated Hospital of Zhejiang University School of Medicine, and conducted in accordance with relevant national guidelines and with patients' consent (ID: 2019ERR-450).

Open Access Statement: This is an Open Access article distributed in accordance with the Creative Commons Attribution-NonCommercial-NoDerivs 4.0 International License (CC BY-NC-ND 4.0), which permits the noncommercial replication and distribution of the article with 
the strict proviso that no changes or edits are made and the original work is properly cited (including links to both the formal publication through the relevant DOI and the license). See: https://creativecommons.org/licenses/by-nc-nd/4.0/.

\section{References}

1. Lauby-Secretan B, Scoccianti C, Loomis D, et al. Body Fatness and Cancer--Viewpoint of the IARC Working Group. N Engl J Med 2016;375:794-8.

2. O'Sullivan J, Lysaght J, Donohoe CL, et al. Obesity and gastrointestinal cancer: the interrelationship of adipose and tumour microenvironments. Nat Rev Gastroenterol Hepatol 2018;15:699-714.

3. Arnold M, Pandeya N, Byrnes G, et al. Global burden of cancer attributable to high body-mass index in 2012: a population-based study. Lancet Oncol 2015;16:36-46.

4. Li Y, Cam J, Bu G. Low-density lipoprotein receptor family: endocytosis and signal transduction. Mol Neurobiol 2001;23:53-67.

5. Goldstein JL, Brown MS. A century of cholesterol and coronaries: from plaques to genes to statins. Cell 2015;161:161-72.

6. Silvente-Poirot S, Poirot M. Cancer. Cholesterol and cancer, in the balance. Science 2014;343:1445-6.

7. Yue S, Li J, Lee SY, et al. Cholesteryl ester accumulation induced by PTEN loss and PI3K/AKT activation underlies human prostate cancer aggressiveness. Cell Metab 2014;19:393-406.

8. Nelson ER, Wardell SE, Jasper JS, et al. 27-Hydroxycholesterol links hypercholesterolemia and breast cancer pathophysiology. Science 2013;342:1094-8.

9. Smith B, Land H. Anticancer activity of the cholesterol exporter ABCA1 gene. Cell Rep 2012;2:580-90.

10. Wang C, Li P, Xuan J, et al. Cholesterol Enhances Colorectal Cancer Progression via ROS Elevation and MAPK Signaling Pathway Activation. Cell Physiol Biochem 2017;42:729-42.

11. Toiyama Y, Fujikawa H, Kawamura M, et al. Evaluation of CXCL10 as a novel serum marker for predicting liver metastasis and prognosis in colorectal cancer. Int J Oncol 2012;40:560-6.

12. Lurje G, Zhang W, Lenz HJ. Molecular prognostic markers in locally advanced colon cancer. Clin Colorectal Cancer 2007;6:683-90.

13. Jacobs RJ, Voorneveld PW, Kodach LL, et al. Cholesterol metabolism and colorectal cancers. Curr Opin Pharmacol 2012;12:690-5.
14. Balkwill F. Cancer and the chemokine network. Nat Rev Cancer 2004;4:540-50.

15. Rokavec M, Oner MG, Li H, et al. IL-6R/STAT3/ miR-34a feedback loop promotes EMT-mediated colorectal cancer invasion and metastasis. J Clin Invest 2014;124:1853-67.

16. Iliopoulos D, Hirsch HA, Struhl K. An epigenetic switch involving NF-kappaB, Lin28, Let-7 MicroRNA, and IL6 links inflammation to cell transformation. Cell 2009;139:693-706.

17. Nielsen SF, Nordestgaard BG, Bojesen SE. Statin use and reduced cancer-related mortality. N Engl J Med 2012;367:1792-802.

18. Bardou M, Barkun A, Martel M. Effect of statin therapy on colorectal cancer. Gut 2010;59:1572-85.

19. Stocks T, Lukanova A, Bjorge T, et al. Metabolic factors and the risk of colorectal cancer in 580,000 men and women in the metabolic syndrome and cancer project (Me-Can). Cancer 2011;117:2398-407.

20. Gauthaman K, Fong CY, Bongso A. Statins, stem cells, and cancer. J Cell Biochem 2009;106:975-83.

21. McDonald JG, Smith DD, Stiles AR, et al. A comprehensive method for extraction and quantitative analysis of sterols and secosteroids from human plasma. J Lipid Res 2012;53:1399-409.

22. Wang C, Shao L, Pan C, et al. Elevated level of mitochondrial reactive oxygen species via fatty acid betaoxidation in cancer stem cells promotes cancer metastasis by inducing epithelial-mesenchymal transition. Stem Cell Res Ther 2019;10:175.

23. Murphy MP. How mitochondria produce reactive oxygen species. Biochem J 2009;417:1-13.

24. Arismendi-Morillo G. Electron microscopy morphology of the mitochondrial network in human cancer. Int J Biochem Cell Biol 2009;41:2062-8.

25. Zheng X, Qian Y, Fu B, et al. Mitochondrial fragmentation limits NK cell-based tumor immunosurveillance. Nat Immunol 2019;20:1656-67.

26. Ikonen E. Cellular cholesterol trafficking and compartmentalization. Nat Rev Mol Cell Biol 2008;9:125-38.

27. Nelson ER, Chang CY, McDonnell DP. Cholesterol and breast cancer pathophysiology. Trends Endocrinol Metab 2014;25:649-55.

28. Kuzu OF, Noory MA, Robertson GP. The Role of Cholesterol in Cancer. Cancer Res 2016;76:2063-70.

29. Kloudova A, Guengerich FP, Soucek P. The Role of Oxysterols in Human Cancer. Trends Endocrinol Metab 
Page 16 of 16

2017;28:485-96.

30. Ma X, Bi E, Lu Y, et al. Cholesterol Induces CD8(+) T Cell Exhaustion in the Tumor Microenvironment. Cell Metab 2019;30:143-156.e5.

31. Yang W, Bai Y, Xiong Y, et al. Potentiating the antitumour response of CD8(+) T cells by modulating cholesterol metabolism. Nature 2016;531:651-5.

32. Esteve E, Ricart W, Fernandez-Real JM. Dyslipidemia and inflammation: an evolutionary conserved mechanism. Clin Nutr 2005;24:16-31.

33. Memon RA, Staprans I, Noor M, et al. Infection and inflammation induce LDL oxidation in vivo. Arterioscler Thromb Vasc Biol 2000;20:1536-42.

34. Schulz O, Hammerschmidt SI, Moschovakis GL, et al. Chemokines and Chemokine Receptors in Lymphoid Tissue Dynamics. Annu Rev Immunol 2016;34:203-42. 35. Palucka K, Banchereau J. Cancer immunotherapy via

Cite this article as: Wang C, Zou Y, Pan C, Shao L, Ding Z, Zhang Y, Ye J, Li P, Ren Y, Zhu C. Prognostic significance of chemokines CCL11 and CCL5 modulated by low-density lipoprotein cholesterol in colon cancer patients with normal body mass index. Ann Transl Med 2021;9(3):202. doi: 10.21037/ atm-20-1604
Wang et al. CCL11 and CCL5 modulated by LDL-C in colon cancers

dendritic cells. Nat Rev Cancer 2012;12:265-77.

36. Gardner A, Ruffell B. Dendritic Cells and Cancer Immunity. Trends Immunol 2016;37:855-65.

37. Conrad C, Gregorio J, Wang YH, et al. Plasmacytoid dendritic cells promote immunosuppression in ovarian cancer via ICOS costimulation of Foxp3(+) T-regulatory cells. Cancer Res 2012;72:5240-9.

38. Treilleux I, Blay JY, Bendriss-Vermare N, et al. Dendritic cell infiltration and prognosis of early stage breast cancer. Clin Cancer Res 2004;10:7466-74.

39. Li H, Liu Y, Lan S, et al. Small-Cell Lung Cancer Derived CD33+ Myeloid-Suppressor Cell Inhibits T Cell Function. J Biomater Tissue Eng 2018;8:267-72.

40. Cordes SF, Gustafson MP, Zhang Z, et al. Expression profiling of suppressive monocytes (CD14+HLA-DRlow/ neg) in cancer patients. Journal for Immunotherapy of Cancer 2013;1. 


\section{Serum cholesterol and oxysterols measurement}

Informed consent was acquired from all the patients. Human serum samples were obtained from 129 individuals in the Department of Gastroenterology of the Second Affiliated Hospital of Zhejiang University School of Medicine. The serum cholesterol and oxysterols were quantified by usingUPLC-MS/ MS. Generally, the collected samples were stored at $-80{ }^{\circ} \mathrm{C}$, and equilibrated to room temperature within 15 mins. After homogeneity by repeatedly pipetting up and down, 200 $\mu \mathrm{L}$ of serum were added drop-wise to $3 \mathrm{~mL}$ of the 1:1 mixture of dichloromethane (1060441000, Sigma-Aldrich): methanol (1060071000, Sigma-Aldrich) solution with $50 \mu \mathrm{g} / \mathrm{mL}$ butylated hydroxytoluene (47168, Sigma-Aldrich) after sparged with $\mathrm{N} 2$ for $10 \mathrm{~min}$. Then the sample tube was flushed with $\mathrm{N} 2$, placed in a $30{ }^{\circ} \mathrm{C}$ ultrasonic bath for $10 \mathrm{~min}$ and centrifuged at 3,500 rpm for $5 \mathrm{~min}$ at room temperature. After that, the organic layer was collected. For hydrolysis, an aliquot of $\mathrm{KOH}$ $(10 \mathrm{~N})$ were added directly to the extract to efficiently hydrolyzed steryl esters to free sterols after 1.5 hr incubation at $35^{\circ} \mathrm{C}$. Following hydrolysis, $3 \mathrm{ml}$ Dulbecco's phosphate-buffered saline (DPBS) was added to each sample. Following vortexing and centrifugation at 3,500 rpm for $5 \mathrm{~min}$ at $25^{\circ} \mathrm{C}$, the organic layer was collected. Three ml dichloromethane was added to the remaining sample. After vortexing and centrifugation at 3,500 rpm for $5 \mathrm{~min}$ at $25^{\circ} \mathrm{C}$, the organic layer was transferred to the initial sample as collected above. The hydrolyzed samples were dried under N2 overnight. The extracted and dried serum samples were dissolved in $1 \mathrm{ml}$ hexane, and then transferred to the aminopropyl SPE column. Sterols were then eluted from the column with CHCL3: methanol, and dried under N2 overnight. The dried samples were then dissolved in $500 \mu \mathrm{L}$ methanol to prepared for further analysis. Derivatization of sterols was performed by adding $100 \mu \mathrm{l}$ of 1:1 pyridine:MTBSTFA (1\% TBDMCS) with $2 \mathrm{mg} / \mathrm{ml} \mathrm{NH4I} \mathrm{after} 50 \mu \mathrm{L}$ sample was dried under N2. Then, the derivatized sample was dries under N2, and then dissolved in $200 \mu \mathrm{L}$ of hexane for further analysis. Quantitative analysis of cholesterol and oxysterols was performed using UPLC-MS-ESI. 

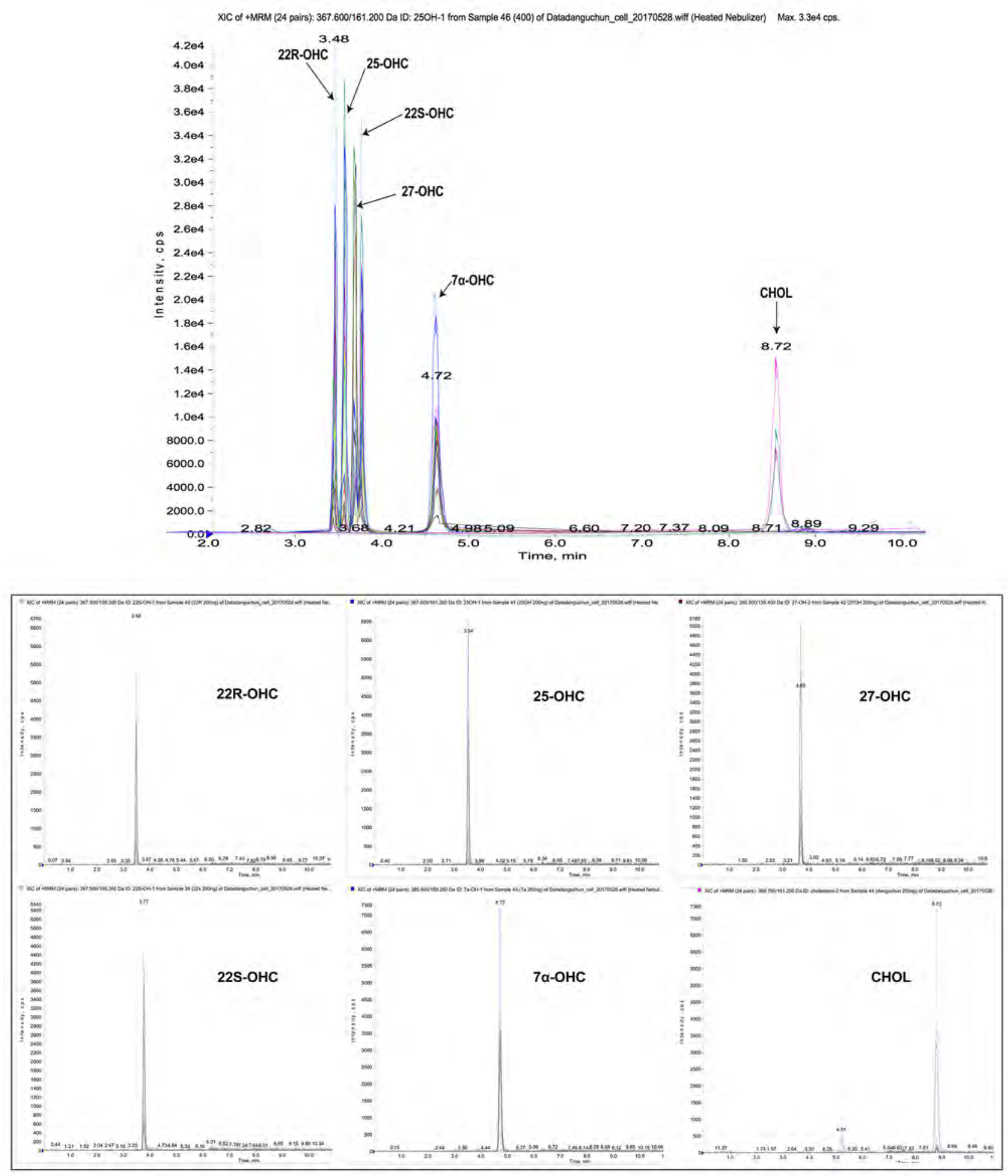

Supplement Figure 1 Chromatograms for cholesterol (CHOL), 22R-OHC, 22S-OHC, 25-OHC, 27-OHC and 7 $\alpha$-OHC. (A-B) Chromatograms for cholesterol (CHOL), 22R-OHC, 22S-OHC, 25-OHC, 27-OHC and $7 \alpha-\mathrm{OHC}$ together and individually. 

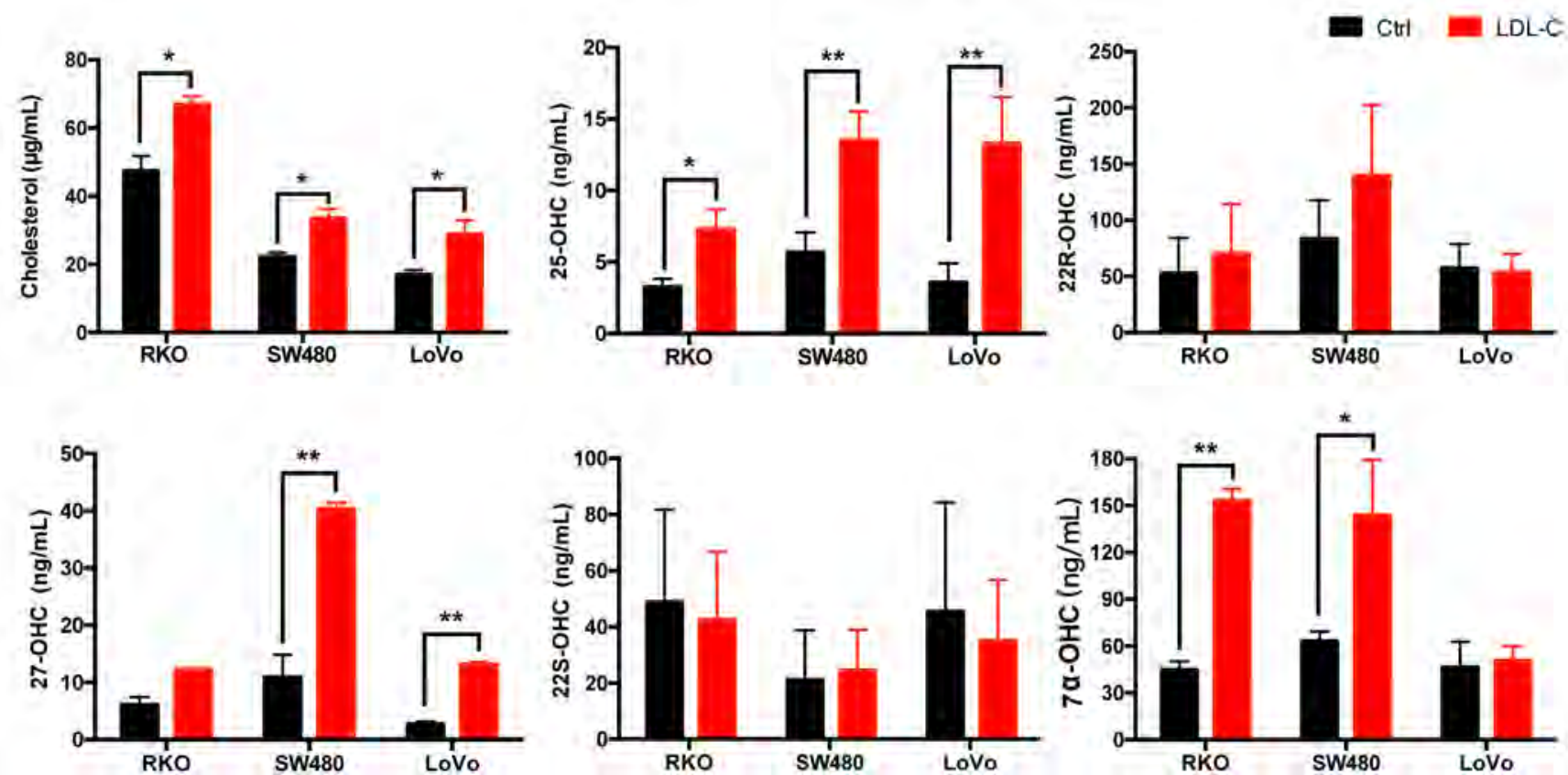

Supplement Figure 2 Low-density lipoprotein cholesterol (LDL-C) significantly increased the intracellular levels of 25-OHC, 27-OHC and $7 \alpha-\mathrm{OHC}$ in RKO, SW480, and LoVo colon cancer cells. ${ }^{*} \mathrm{p}<0.05,{ }^{* *} \mathrm{p}<0.01$.

(A)

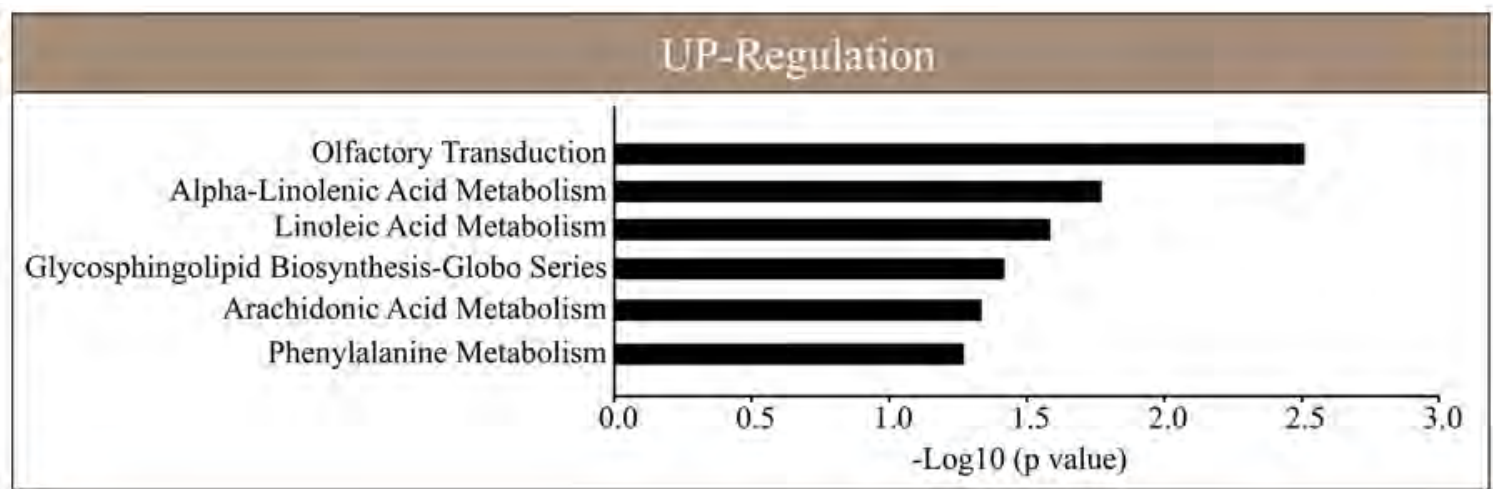

(B)

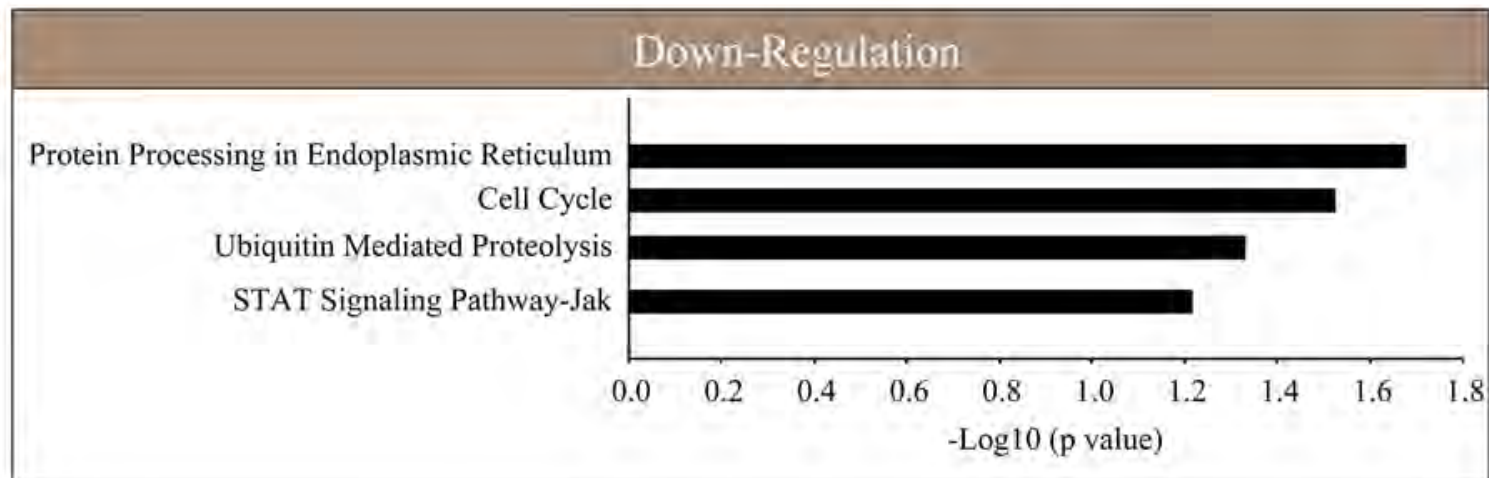

Supplement Figure 3 Significantly enriched KEGG terms $(\mathrm{P}<0.05)$ in the up- regulated or down-regulated genes. KEGG terms were sorted based on P-values. 


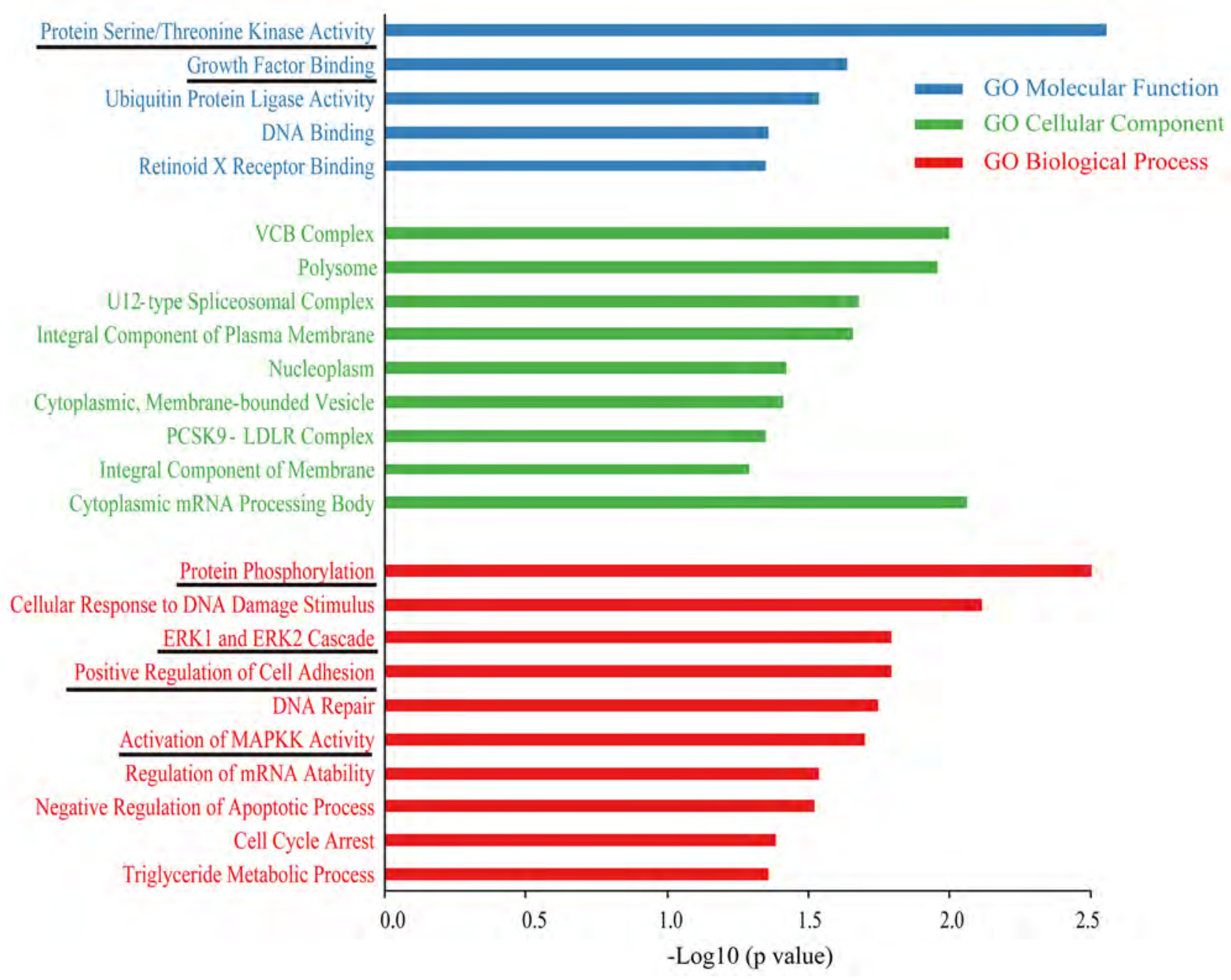

Supplement Figure 4 Significantly enriched Gene ontology (GO) terms $(\mathrm{P}<0.05)$ in the down-regulated genes. GO terms belong to molecular functions, cellular components, and biological processes were shown in blue, green, and red, respectively. GO terms were sorted based on P-values. 


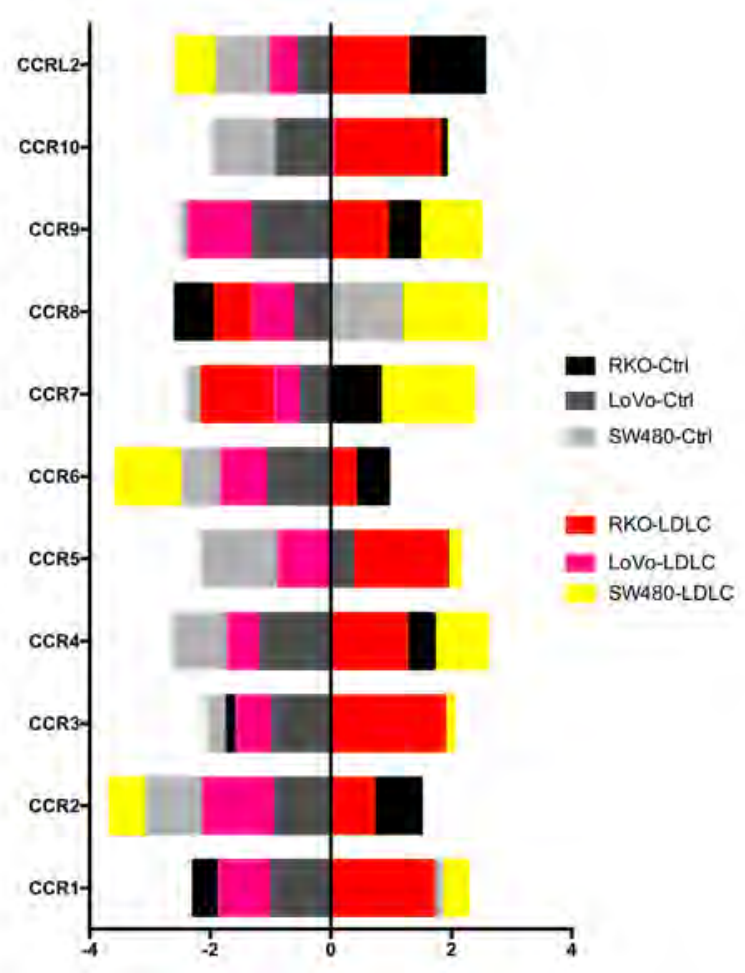

Supplement Figure 5 Low-density lipoprotein cholesterol (LDL-C) had no influence on CCL chemokine family receptors (CCR). The changes of CCR when incubated with LDL-C $(100 \mu \mathrm{g} / \mathrm{ml})$.

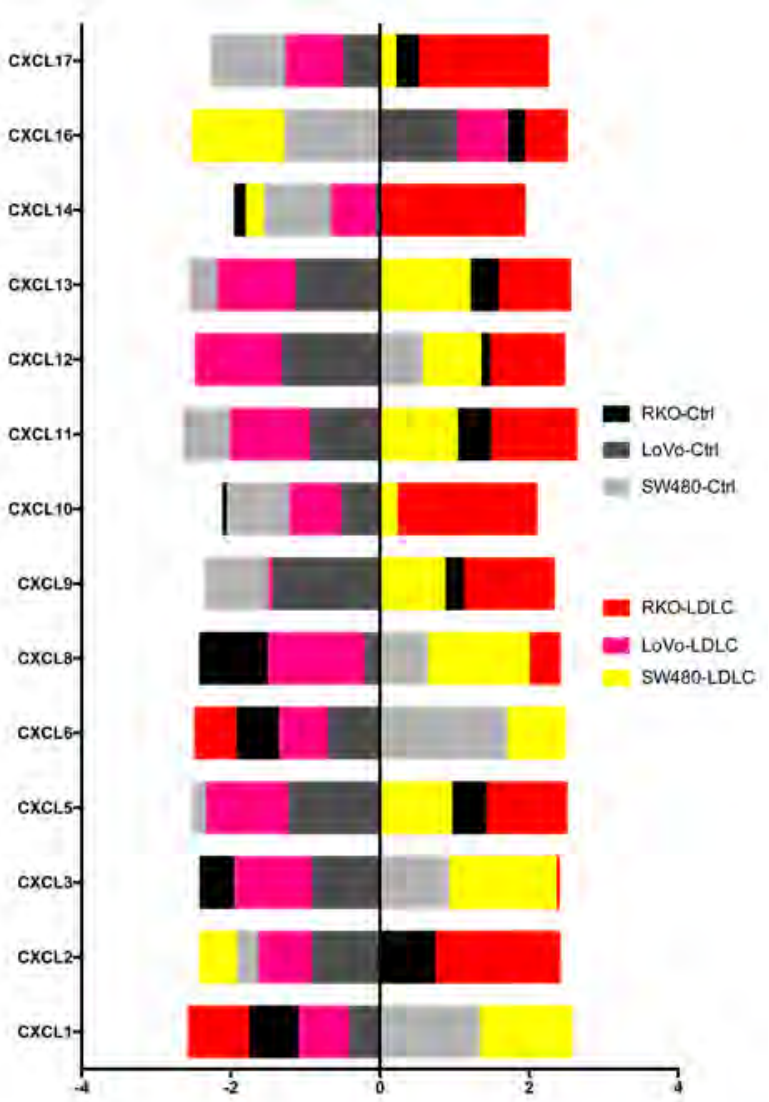

Supplement Figure 6 Low-density lipoprotein cholesterol (LDL-C) had no influence on CXCL chemokine family. The changes of CXCL when incubated with LDL-C (100 $\mu \mathrm{g} / \mathrm{ml})$. 


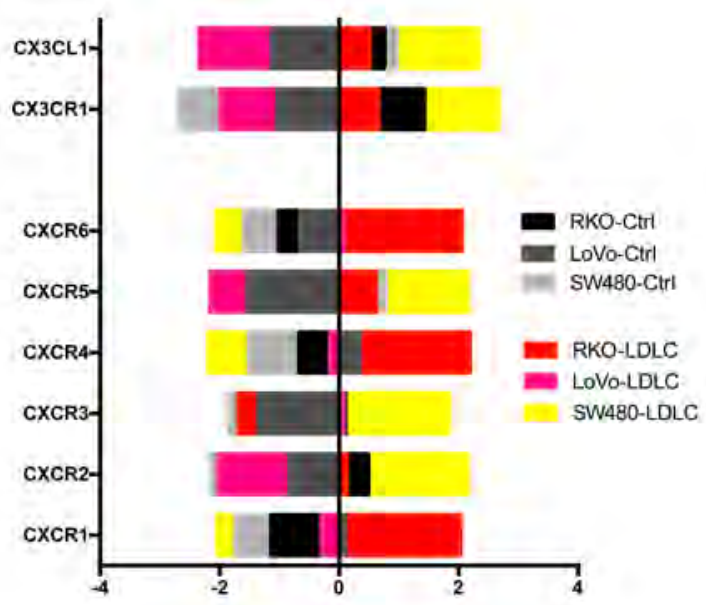

Supplement Figure 7 Low-density lipoprotein cholesterol (LDL-C) had no influence on CXCL chemokine family receptors (CXCR), CX3CL1 and CX3CR1. The changes of CXCR, CX3CL1 and CX3CR1 when incubated with LDL-C $(100 \mu \mathrm{g} / \mathrm{ml})$.

TNM Stage

\begin{tabular}{|llll|}
\hline I II & III \\
\hline
\end{tabular}

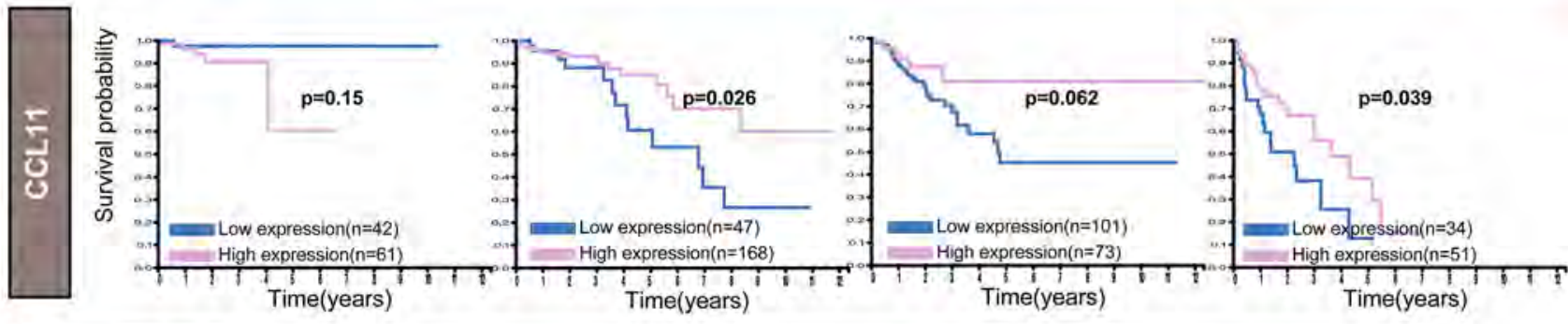

\begin{tabular}{llllll}
\hline 5year & CCL11 high & $61 \%$ & $85 \%$ & $81 \%$ & $39 \%$ \\
\cline { 2 - 5 } survival & CCL11 low & $98 \%$ & $61 \%$ & $45 \%$ & $13 \%$ \\
\hline
\end{tabular}

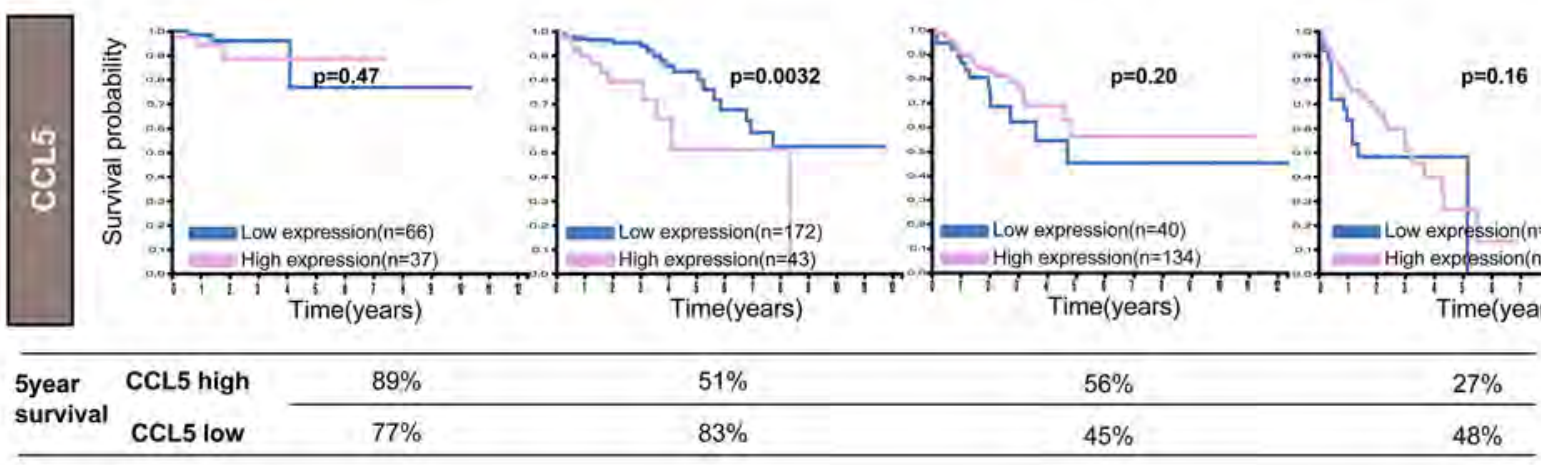

Supplement Figure 8 The decreased CCL11 expression and increased CCL5 expression were negatively correlated with 5-year overall survival of colorectal cancer patients. 
(A)

\begin{tabular}{clc}
\hline \multirow{2}{*}{ Chemokine } & \multicolumn{2}{c}{ Receptor } \\
\cline { 2 - 3 } & \multicolumn{1}{c}{ Agonistic Antagonistic } \\
\hline CCL5 & CCR1, CCR3, CCR5 \\
CCL11 & CCR3, CCR5 & CXCR3, CCR2
\end{tabular}

(B)
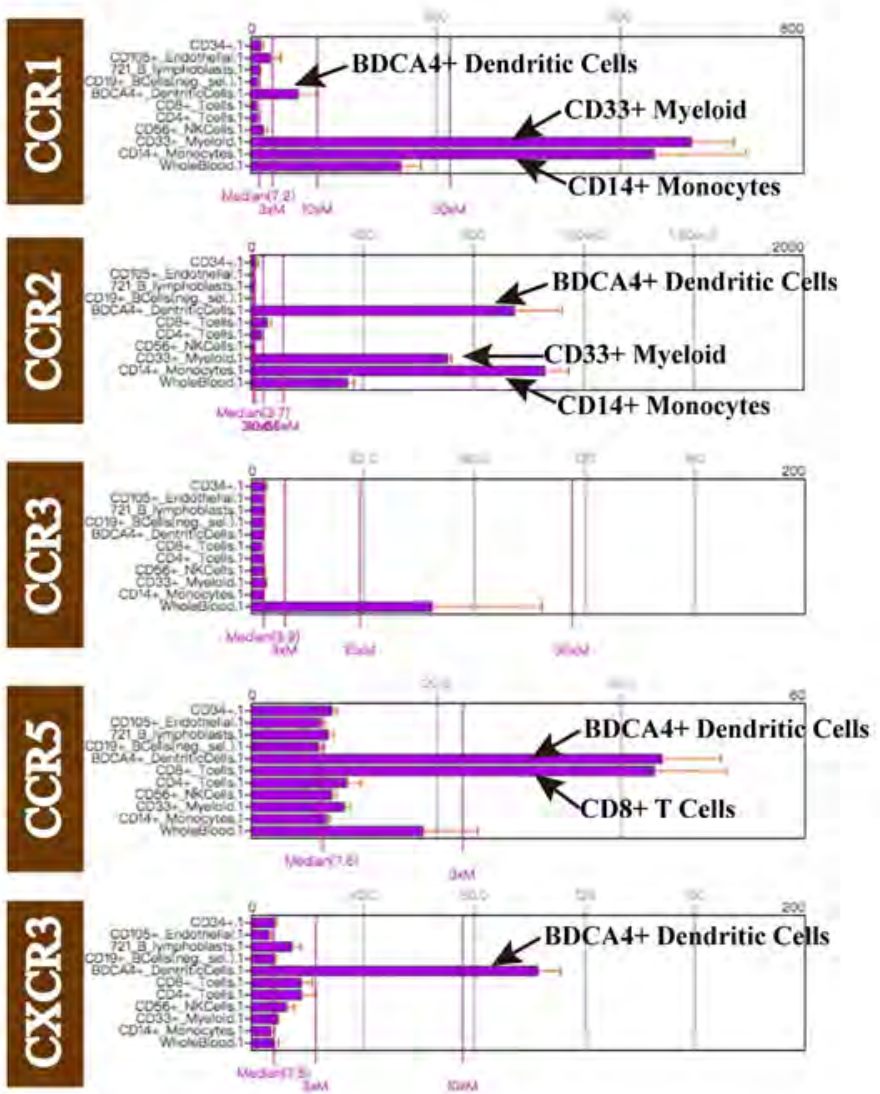

Supplement Figure 9 Decreased CCL11 and increased CCL5 might lead to the recruitment and activation of BDCA4+ Dendritic Cells, CD33+ Myeloid, and CD14+ Monocytes. (A) Chemokines bind receptors of CCL5 and CCL11, such CCL 5 binds to CCR1/3/5 and CCL11 binds to CCR3/5 (agonistic receptor) and CCR2, CXCR3 (antagonistic receptor). (B) The tissue-specific pattern of CCR1, CCR2, CCR3, CCR5, and CXCR3 mRNA expression. Data from BioGPS. (CCR1 expression pattern: http://ds.biogps.org/?dataset=GSE1133\&gene=1230; CCR2 expression pattern: http://ds.biogps.org/?dataset=GSE1133\&gene=729230; CCR3 expression pattern: http://ds.biogps. org/? dataset=GSE1133\&gene=1232; CCR5 expression pattern: http://ds.biogps.org/? dataset=GSE1133\&gene=1234; CXCR3 expression pattern: http://ds.biogps.org/?dataset=GSE1133\&gene=2833). 